\title{
Design and Manufacturing of Tow-Steered Composite Shells Using Fiber Placement
}

\author{
K. Chauncey $\mathrm{Wu}^{*}$ \\ NASA Langley Research Center, Hampton, VA 23681 \\ Brian F. Tatting ${ }^{\dagger}$ \\ ADOPTECH, Inc., Blacksburg, VA 24060 \\ Brett H. Smith \\ NASA Marshall Space Flight Center, Huntsville, AL 35812 \\ Randy S. Stevens, § Gina P. Occhipinti, Jonathan B. Swift ${ }^{\#}$ and David C. Achary ${ }^{* *}$ \\ Lockheed Martin Space Systems Company - Michoud Operations, New Orleans, LA 70129 \\ and \\ Robert P. Thornburgh ${ }^{\dagger \dagger}$ \\ U.S. Army Research Laboratory, Hampton, VA 23681
}

\begin{abstract}
Advanced composite shells that may offer the potential to improve the structural performance of future aircraft fuselage structures were developed under this joint NASAindustry collaborative effort. Two cylindrical shells with tailored, tow-steered layups and continuously varying fiber angle orientations were designed and built at the National Center for Advanced Manufacturing - Louisiana Partnership. The shells were fabricated from unidirectional IM7/8552 graphite-epoxy pre-preg slit tape material fiber-placed on a constant-diameter mandrel. Each shell had the same nominal 8-ply $[ \pm 45 / \pm \Theta]_{S}$ layup, where the nominal fiber angle $\Theta$ in the tow-steered plies varied continuously from 10 degrees along the crown to 45 degrees on each side, then back to 10 degrees on the keel. One shell was fabricated with all 24 tows placed during each pass of the fiber placement machine, resulting in many tow overlaps on the shell surface. The fiber placement machine's individual tow cut/restart capability was also used to manufacture a second shell with tow drops and a more uniform laminate thickness. This paper presents an overview of the detailed design and manufacturing processes for these shells, and discusses issues encountered during their fabrication and post-cure evaluation. Future plans for structural testing and analyses of the shells are also discussed.
\end{abstract}

* Aerospace Engineer, Structural Mechanics and Concepts Branch, RTD, Mail Stop 190, AIAA Member.

$\dagger$ Research Scientist, 2000 Kraft Drive, Suite 1204.

* Aerospace Engineer, Materials and Processes Laboratory, Code EM03, Bldg. 4601/4344.

$\S$ Materials and Processing Lead, Composites Products and Technology Group, 13800 Old Gentilly Road, Mail Stop 4800.

I Materials Engineer, Composites Products and Technology Group, 13800 Old Gentilly Road, Mail Stop 4800.

\# Design Engineer, Composites Products and Technology Group, 13800 Old Gentilly Road, Mail Stop 4800.

** Composites Chief Engineer, Composites Products and Technology Group, 13800 Old Gentilly Road, Mail Stop 4800.

†† Aerospace Engineer, Vehicle Technology Directorate, NASA LaRC, Mail Stop 340, AIAA Senior Member. 


\section{Introduction}

Over the past two decades, commercial fiber placement systems ${ }^{1}$ have become widely used to manufacture complex aerospace composite structures, ${ }^{2}$ resulting in associated reductions in touch labor time, material wastage and part counts. Concurrent research was also performed to design advanced composite structures ${ }^{3-11}$ that have improved structural performance and are fabricated using fiber placement. To achieve these performance improvements, the tow steering capabilities inherent in the fiber placement machines are typically used to align the composite fibers with the desired structural load paths. While most of the research performed to date has been done on composite plates, ${ }^{12-15}$ another class of composite structure with many aerospace applications is the cylindrical shell, which is now being used for commercial aircraft fuselages ${ }^{16}$ and may also be used as primary structures for load-bearing propellant tanks for future space launch vehicles. ${ }^{17}$

An early investigation into the performance of segmented cylindrical shell configurations was an analytical and experimental study 18,19 which investigated the structural response under axial end shortening of two segmented shells with uniform $\left[ \pm 45 / 0_{2}\right]_{\mathrm{S}}$ or $\left[{ }^{4} 45 / 90_{2}\right]_{\mathrm{S}}$ layups in both crown and keel segments, and uniform $[ \pm 45]_{2 \mathrm{~S}}$ layups in the shell side segments. Overlapping splices were located around the shell circumference to transition between adjacent segments. During both the analyses and tests, applied axial loads were redistributed to the shell segments with higher axial stiffnesses.

Further detailed analyses ${ }^{9}$ developed the fundamental mechanics underlying the structural stability response of cylindrical variable stiffness shells. One of the shell configurations evaluated using linear membrane theory had a continuous circumferential stiffness variation under arbitrary loading. Significant performance improvements were achieved through load redistribution and an altered buckling response, especially for cases with circumferentially varying bending and shear loads. Both the modified load redistribution and buckling response were themselves byproducts of the circumferential stiffness variation.

Recent research ${ }^{20}$ on the optimal design and manufacture of cylindrical shells in bending predicted that improvements in buckling moments are achievable using the variable stiffness concept. The composite shell described therein had a tailored, tow-steered layup with fiber orientation angles that varied continuously around the shell circumference, resulting in a neutral axis shift towards the tension-loaded keel. In addition, the selected layup was asymmetric through the laminate thickness (where the fiber orientation angle varies from ply to ply), resulting in a single port-starboard symmetry plane in the shell.

In a contemporary analytical study, ${ }^{21}$ the tow-steered cylindrical shells studied had a relatively simple 8-ply layup, symmetric through the laminate thickness, which provided two planes of symmetry in the assembled structure. In this study, 17 in.-diameter shells with one tow-steered fiber pattern (see Figure 1) were examined in more detail. In this fiber pattern, the nominal fiber orientation angle $\Theta$ varied continuously from 10 degrees (with respect to the shell axis of revolution) along the shell crown line to 45 degrees on the shell side, and then back to 10 degrees on the keel line. Each fiber path was defined to follow a constant-radius circular arc on the shell surface, with the arc's tangent line oriented between 10 and 45 degrees from the shell axis over one-quarter of the shell circumference.

Two shells with the same $[ \pm 45 / \pm \Theta]_{\mathrm{S}}$ layup, one each with and without tow overlaps, were also evaluated using both closed-form and finite element analyses in this study. Some improvements in static bending stiffness and buckling moment were noted for the shell with overlaps when compared to a quasi-isotropic baseline shell. However, the predicted structural performance of the shell without overlaps was not as good as that of the baseline shell. The static bending stiffnesses of a wide range of shells with separate, uniform fiber-angle crown/keel panels and tow-steered side panels were also examined, indicating that further performance improvements are possible.

Because the majority of the work performed to date on tow-steered composite shells has been either analytical or numerical, most prior studies do not capture the various essential characteristics, weaknesses and issues revealed through fabrication of actual hardware. To address these aspects, this study was initiated to manufacture two advanced composite shells using the same nominal layup described above and in Ref. 21. In this collaborative effort, the detailed design and programming required prior to manufacturing was done by ADOPTECH, Inc. in Blacksburg, Virginia. The shells were then manufactured by Lockheed Martin Space Systems Company - Michoud Operations in New Orleans, Louisiana, using a fiber placement machine (Figure 2) located at the National Center for Advanced Manufacturing - Louisiana Partnership (NCAM) which was built by Ingersoll Machine Tools. NASA Marshall Space Flight Center provided project management and procurement, and NASA Langley Research Center provided the overall technical direction for the project as well as detailed surface assessments performed on the finished shells. 


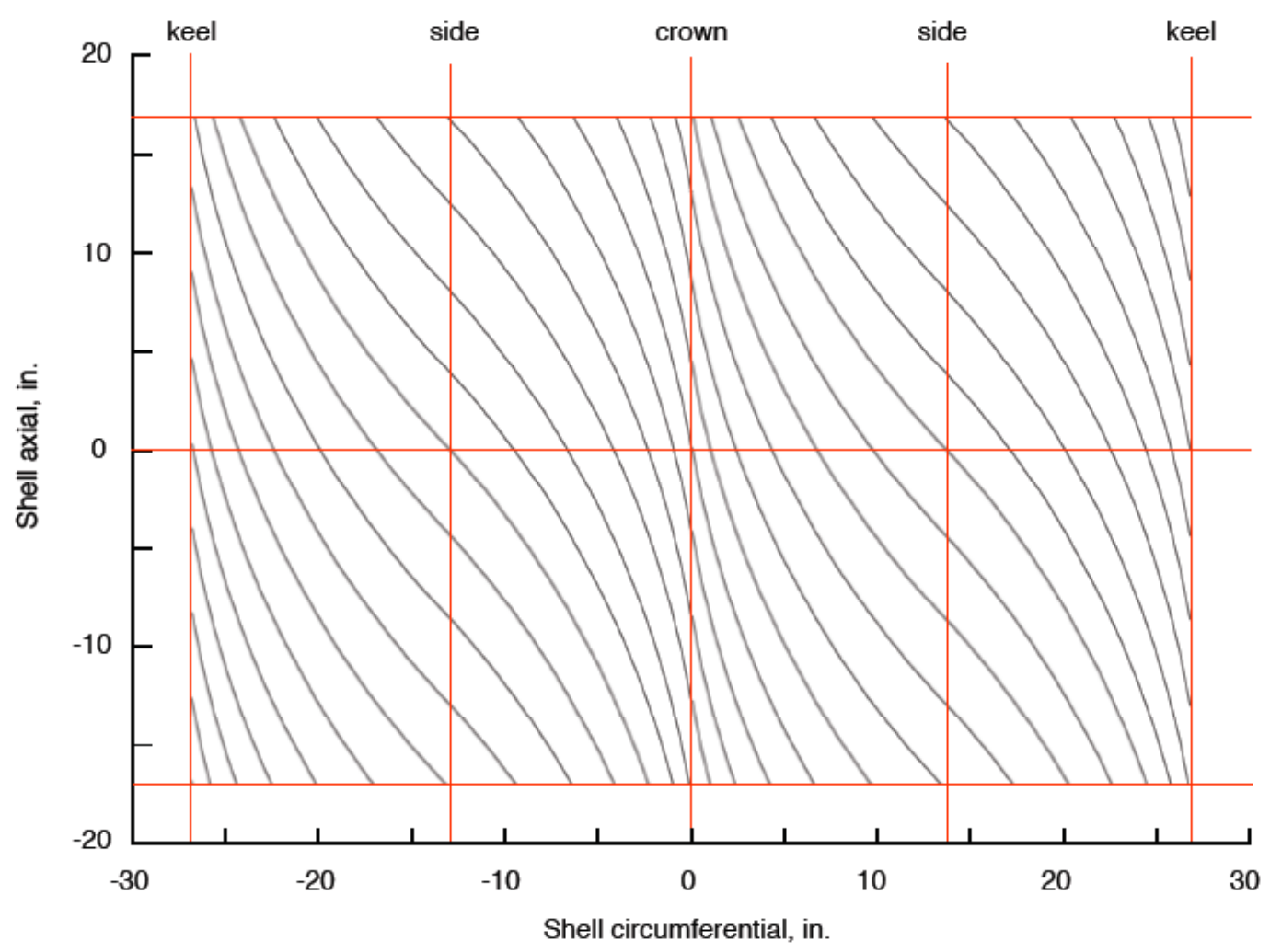

Figure 1. Nominal course centerlines for tow-steered ply.

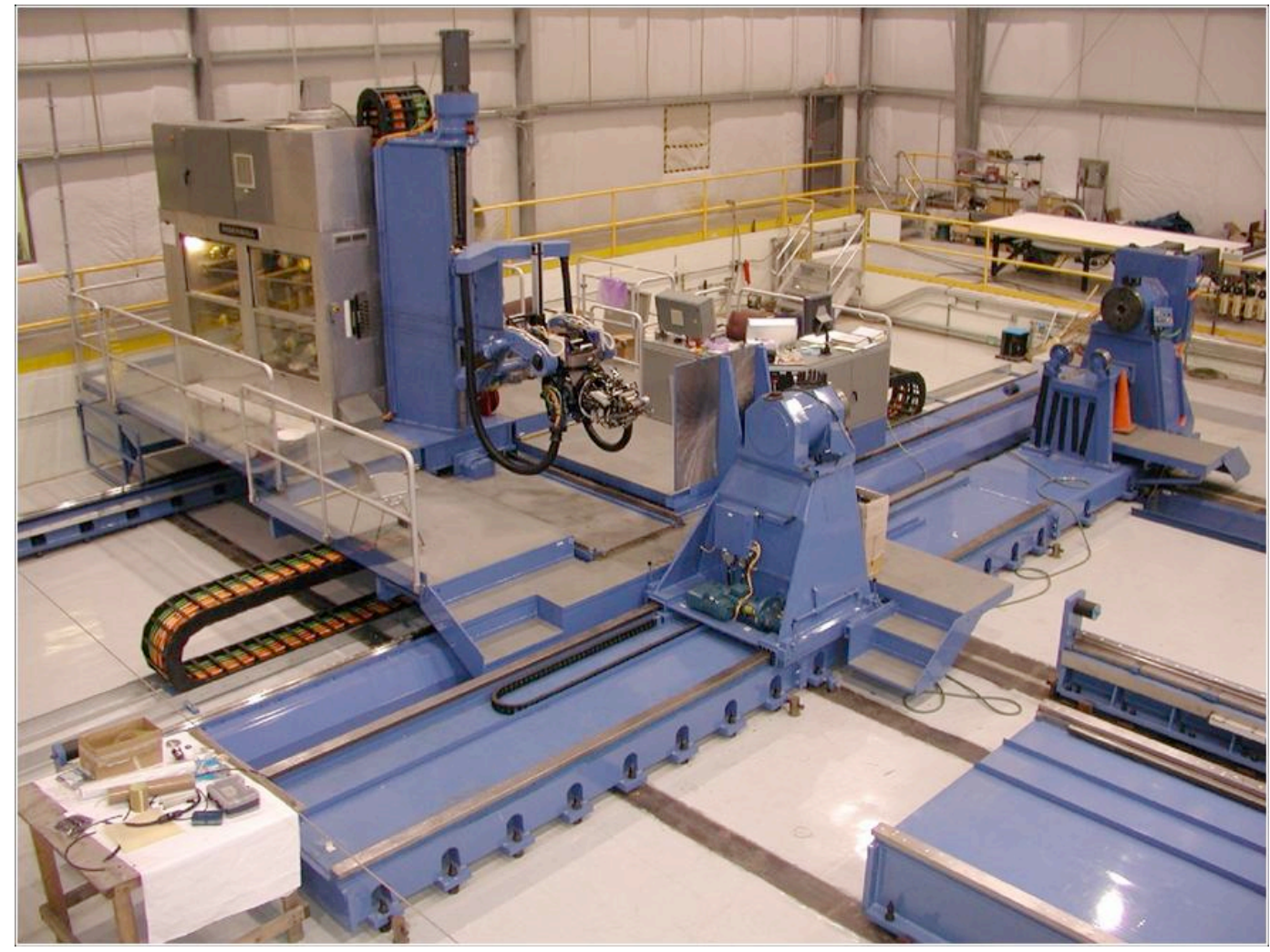

Figure 2. Fiber placement machine. 
Shown in Figure 3, the 34 in.-long shells were fabricated from 1/8 in.-wide unidirectional IM7/8552 graphiteepoxy pre-preg slit tape material placed on an existing, 16.266-in. constant-diameter mandrel. The several inches of additional material placed on each end of the shells are not treated here as part of the 34-in. design length. While each shell had the same nominal 8-ply $[ \pm 45 / \pm \Theta]_{\mathrm{S}}$ tow-steered layup, the first shell, designated as the shell with overlaps, was fabricated with all 24 tows placed during each pass of the fiber placement machine, resulting in a distinctive pattern of tow overlaps on the shell outer surface. The fiber placement machine's individual tow cut/restart capability was also used to manufacture a second shell without overlaps that had a more uniform laminate thickness over the shell surface.

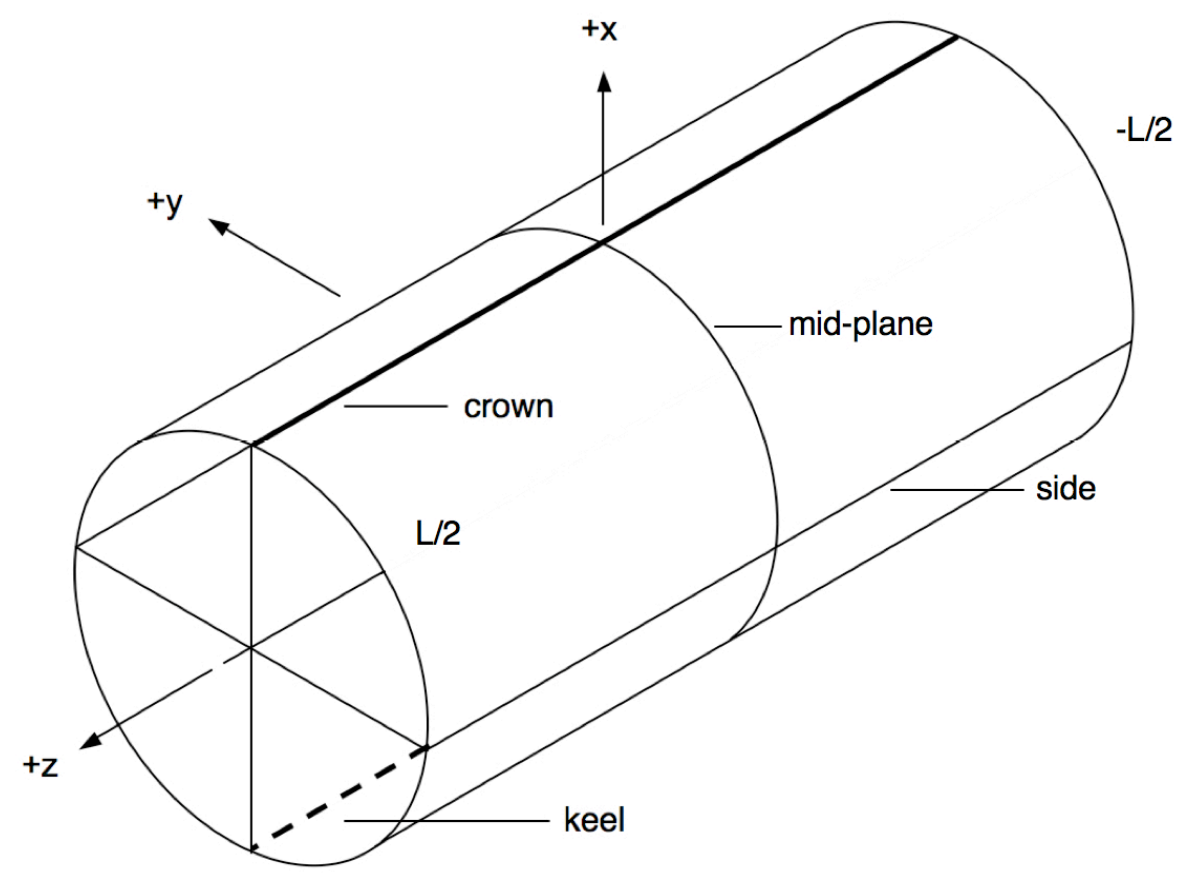

Figure 3. Tow-steered shell schematic.

In this paper, the detailed design and programming effort required to generate the curvilinear steered paths that the fiber placement machine follows around the mandrel are discussed in great detail. An overview of the fabrication of the shells, as well as other relevant issues and concerns encountered during this process, is presented and discussed. After fabrication, a high-precision coordinate measuring machine was used to map the shells' inner and outer surfaces. The surface survey data generated were then processed to determine the initial imperfections and thickness variations in the cured shells, and these results are presented here. Finally, an overview of future plans for the testing and analyses of these tow-steered shells is presented.

\section{Tow Path Design and Programming}

In order to program the tow steered shell for fiber placement, Lockheed Martin personnel collaborated with the engineers at ADOPTECH and Ingersoll for the shell fabrication efforts. The fiber placement program for the tow steering was not programmed in the typical format, but instead relied on customized course data for the steered courses that were then translated into the appropriate format for fiber placement. The necessary course data for the two different part configurations, namely the construction techniques for the shells with and without tow overlaps (see Figures 4 and 5), were generated at ADOPTECH and the final configurations were approved by NASA Langley personnel. The course data contained the path trajectories along with the relevant machine data information and tow mask transition areas for interband dropping and boundary gap/lap regions.

This method of data generation has been used successfully in the past for course generation of curvilinear paths on flat panel structures. The greatest challenge for the cylindrical shell structure was translating the data to the 
cylindrical surface. Since this new surface was developable from a plane, a simple coordinate transformation was all that was needed for correct definition of point locations and vectors (surface normals and path directions).

However, the continuous nature of the cylindrical shell forced a new constraint on the course data to ensure a consistent gap between successive courses around the circumference, especially between the first and last courses. This constraint applied not only to the curvilinear plies but also to the constant-angle plies. To satisfy this constraint, several options are available to the designer, including the number of tows in each course, the number of courses around the circumference, the fiber orientation angle values, and a shift parameter used to set the interband distance between successive courses. These values were adjusted for each ply (since the increasing diameter after each ply was placed slightly altered the underlying surface) until a consistent gap/overlap was achieved for each ply orientation.

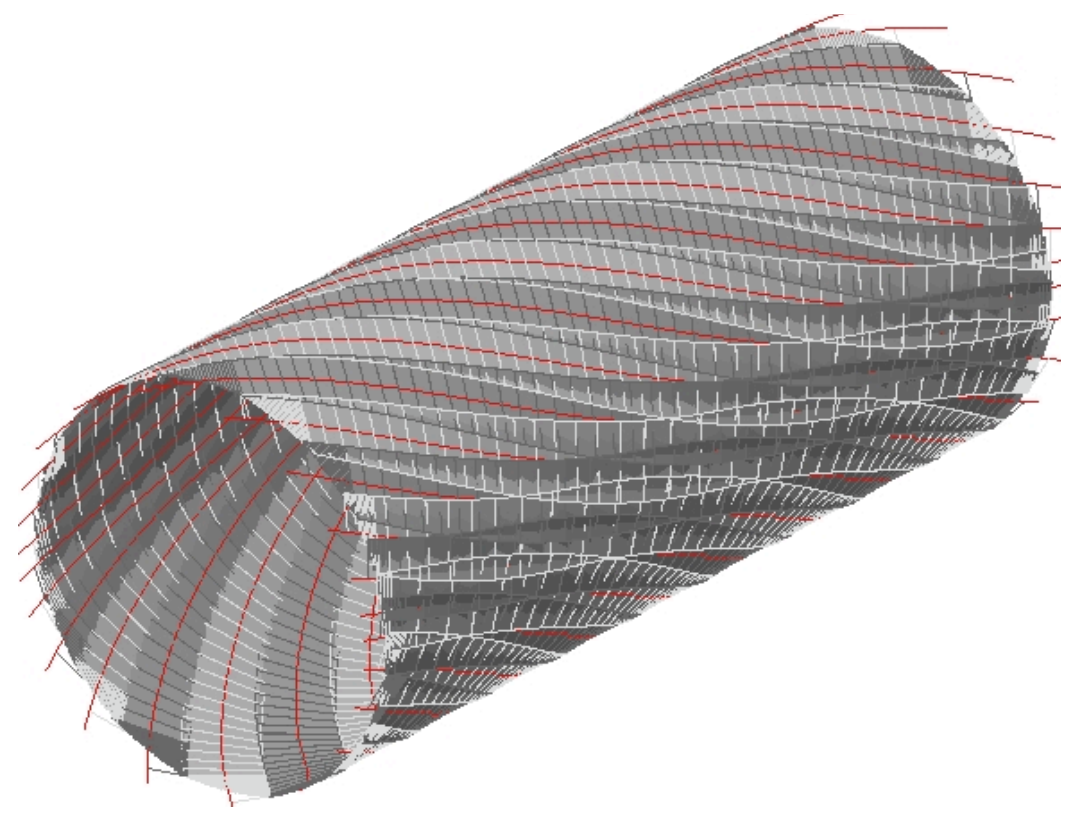

Figure 4. Courses for shell with overlaps.

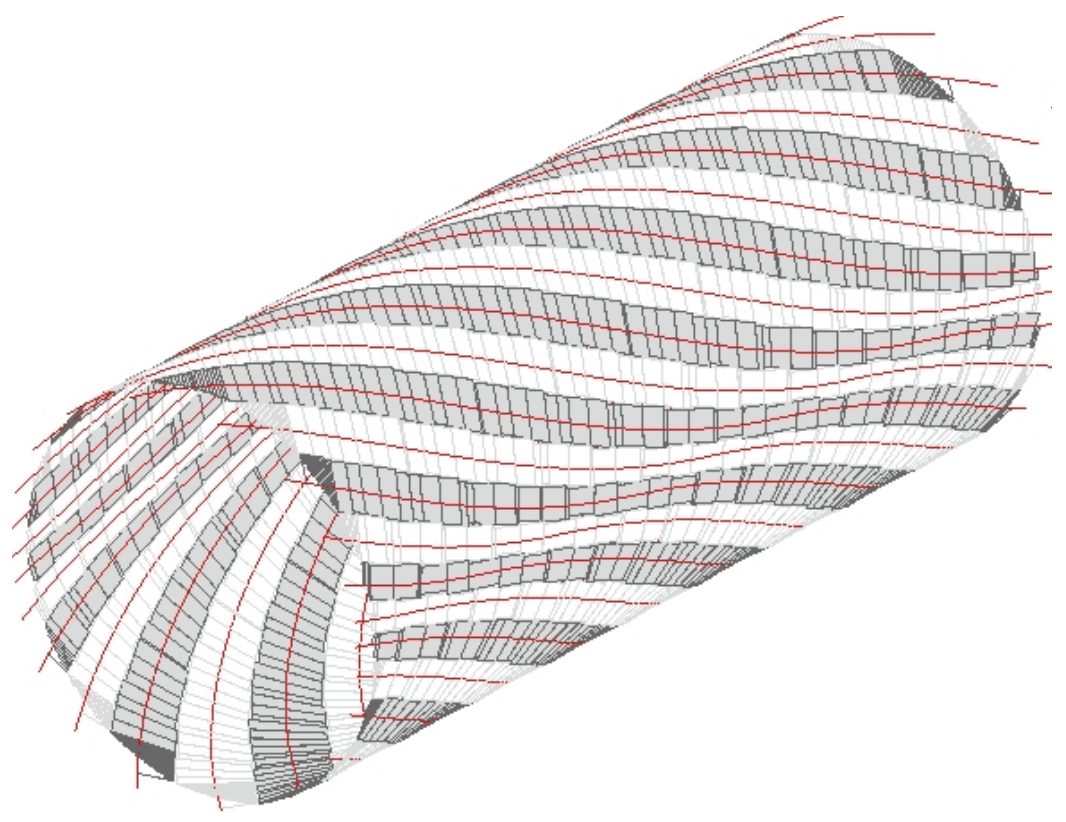

Figure 5. Courses for shell without overlaps. 
Ingersoll translated the course data provided by ADOPTECH into machine control data that can be used for fiber placement using their in-house software. Lockheed Martin provided Ingersoll with a model of the tool mandrel built in CATIA version 5. Included in this model was the fiber placement machine coordinate system (with the origin located at the fiber placement machine headstock), the trunion attachment distance from the headstock to the nominal mandrel surface, and the 1 in.-diameter tooling puck locations on the mandrel. Ingersoll then delivered two sets of machine control data for the tow-steered shells (overlap and tow drop) to Lockheed Martin in traditional project format for fiber placement. Lockheed Martin received the project data from Ingersoll and ran simulations using the Composite Programming System software to check for any machine collisions (see Figure 6). The machine tooling procedure was also simulated and verified. Lockheed Martin then created a ply book (see Figure 7) with both sets of shell data and supplied them to all parties to verify the correct ply orientations. The ply books for both tow steered programs, overlap and tow drop, included reference pictures of each ply orientation along with the Part Sequence File for the shop floor to use as reference material for manufacturing.

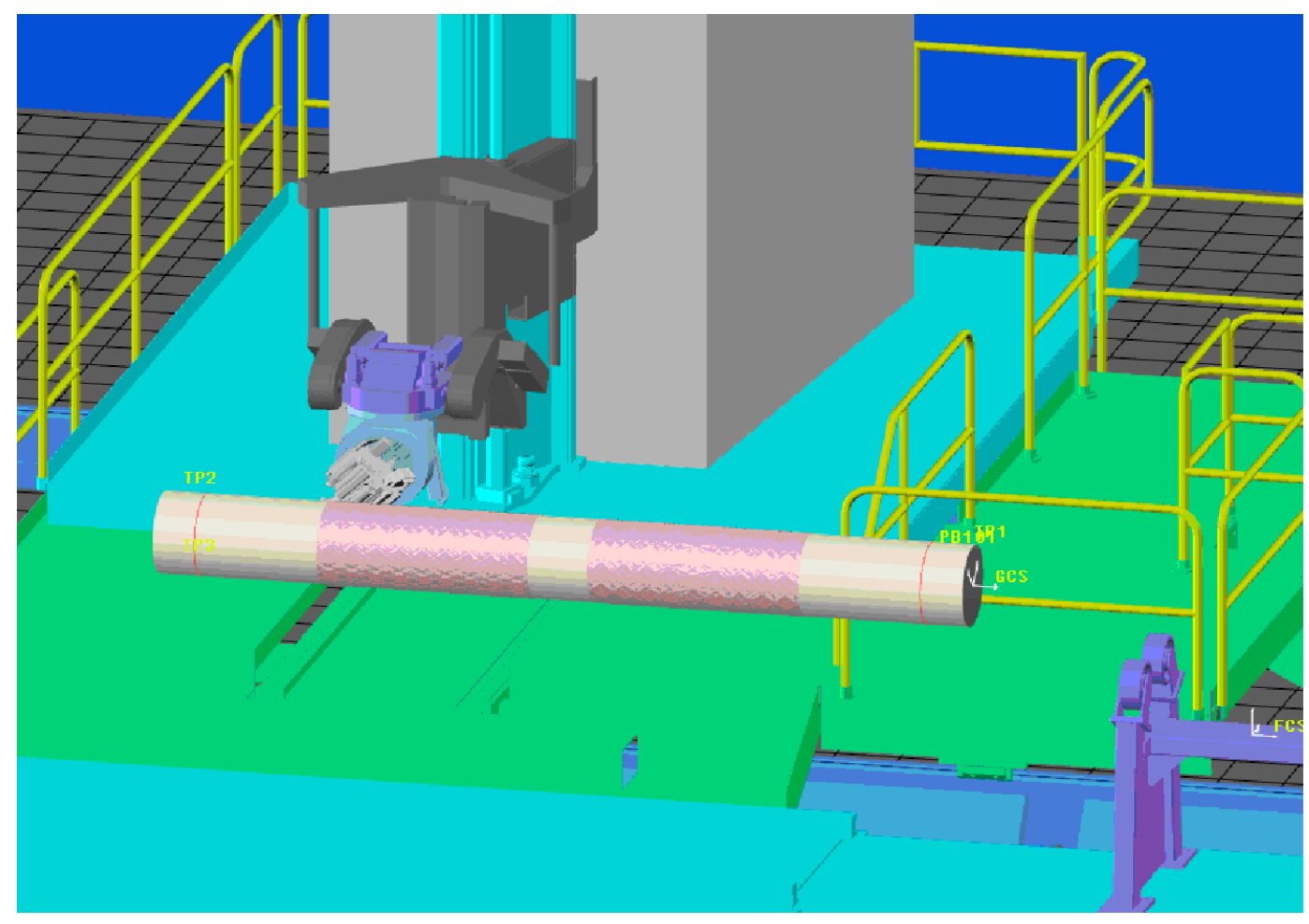

Figure 6. Manufacturing simulation running on CPS software.

After fabrication of the first tow-steered shell, Lockheed Martin asked Ingersoll to regenerate the machine control code for the shells to have the fiber placement machine lay the material down in a bidirectional placement method. The reprogramming was to account for a greater retract distance with the machine head while transitioning from course to course. The reprogramming improved the machine's off-part motion, which reduced the manufacturing time by allowing the machine operators to run the machine at higher speeds between courses. Lockheed Martin received a new set of control data that incorporated the new off-part motion, re-simulated the new code and checked for any discrepancies prior to using it to fabricate the other shell.

\section{Manufacturing of Tow-Steered Shells}

The composite shells were fabricated using the smaller 2.5-meter automated fiber placement machine (FPM) located in the NCAM (see Figure 8). The FPM was loaded with a cylindrical mandrel, shown in Figure 9, that was 16.266 inches in diameter. The tool was inspected for nicks or blemishes and cleaned thoroughly. The area where the shells were going to be placed was then coated with three coats of Frekote $700 \mathrm{NC}$ mold release. The material used for the shells was a Hexcel IM7/8552 graphite/epoxy slit tape (nominal 145 grams/square meter FAW, 34 
percent resin content, and 0.0052-in. cured ply thickness) supplied by Lockheed Martin. The material was 0.125 inches wide and the lot used was VX 6945-A. The machine's head allows a maximum of 24 tows to be placed at one time to form a single course, with a nominal compaction force of $125 \mathrm{lbs}$.

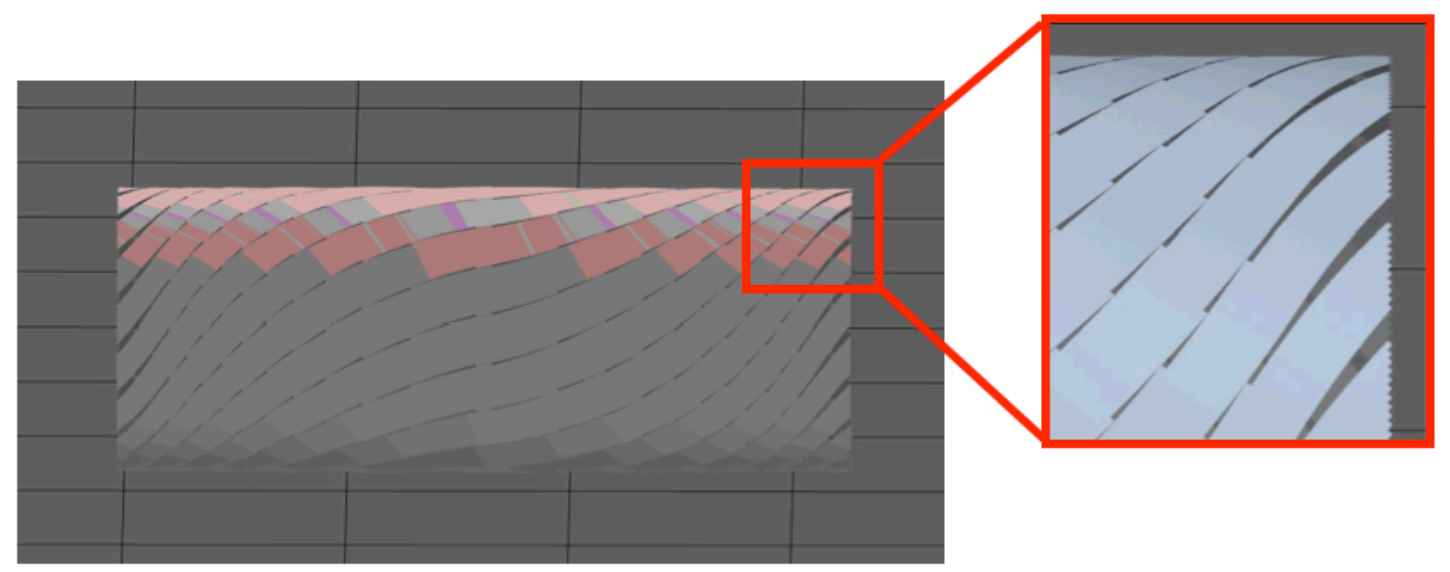

Figure 7. Image of shell without overlaps in ply book taken from CPS.

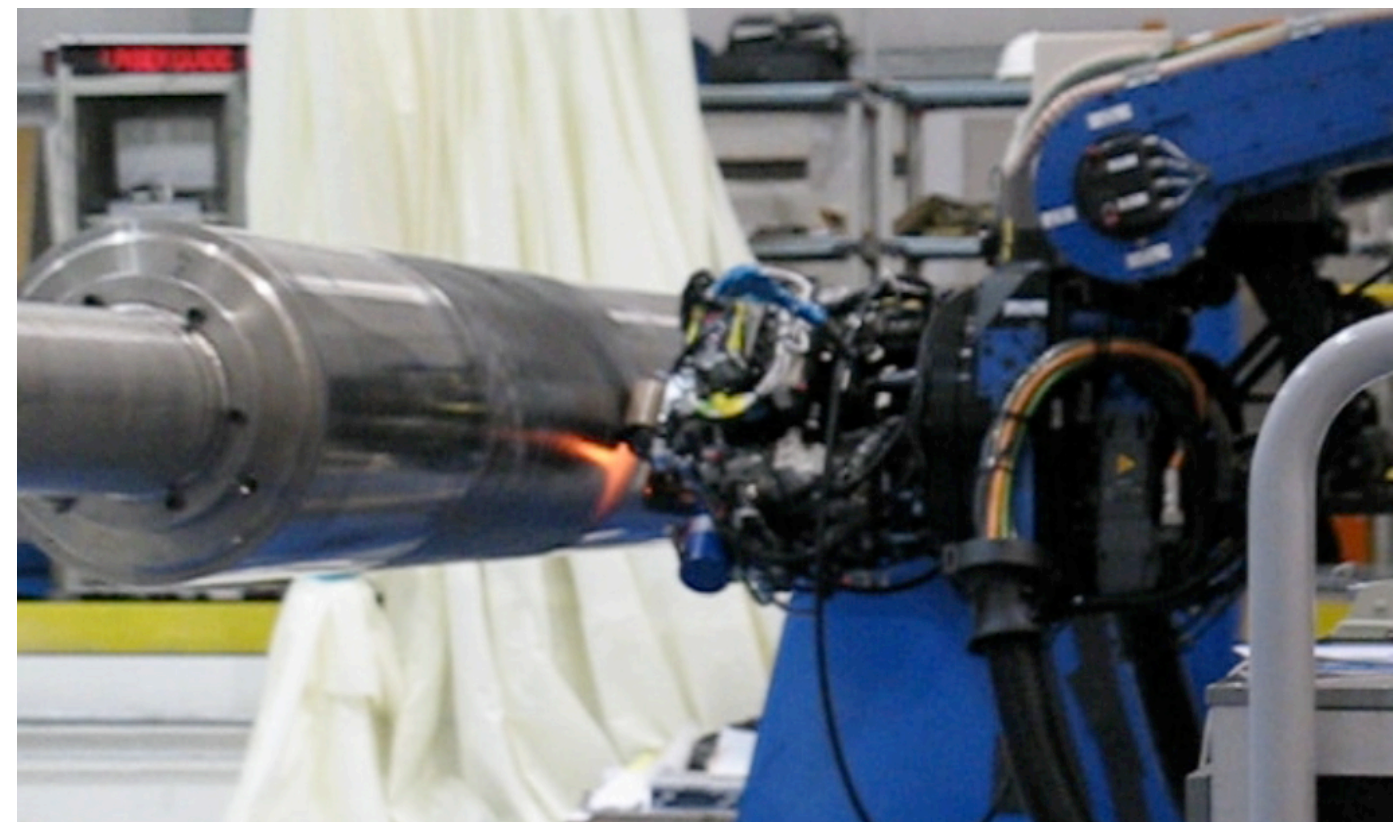

Figure 8. Fiber placement of tow-steered shell.

Both shells were debulked after the first ply was placed on the mandrel. Placement of the first ply during manufacturing is always a little more of a challenge than the rest of the process. In this case, some of the factors involved placing composites on a cold, curved metal surface. Since the bare metal does not give the composite a great surface to adhere to, a tackifier solution is first applied to the mandrel to make it tacky to the touch. Debulking the completed first ply makes all of the tows tight on the tool and gives a good surface for placement of the subsequent plies. After manufacturing of the tow-steered shells was completed, the program part history files were loaded on the Lockheed Martin server. These part history files capture all of the machine parameters and run time data generated during fiber placement of the shells. 


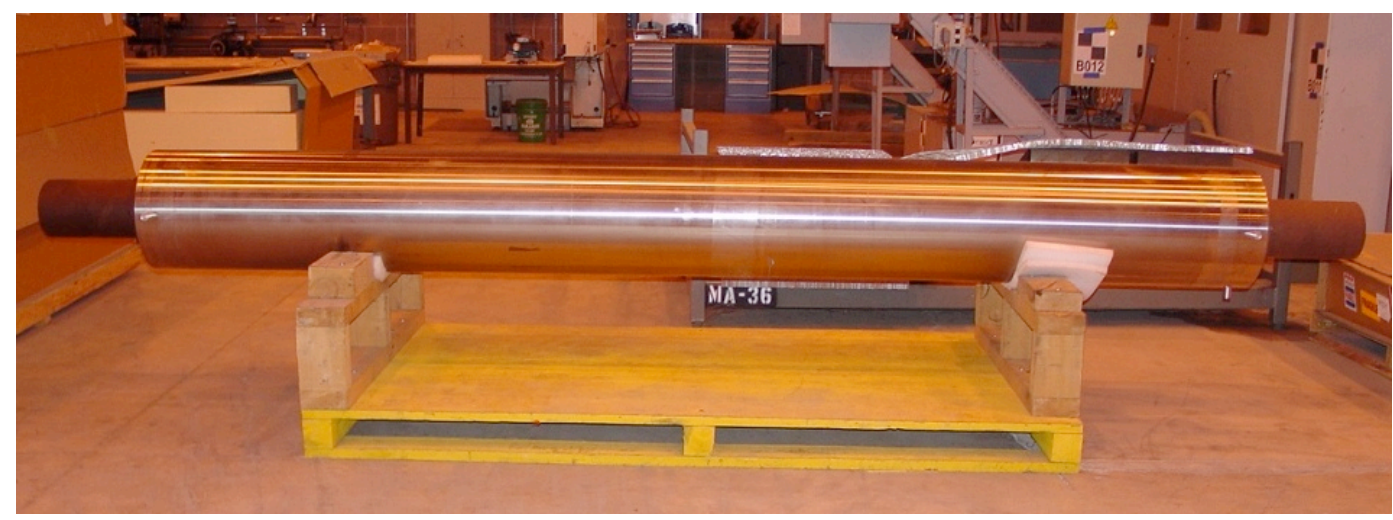

Figure 9. Tooling mandrel.

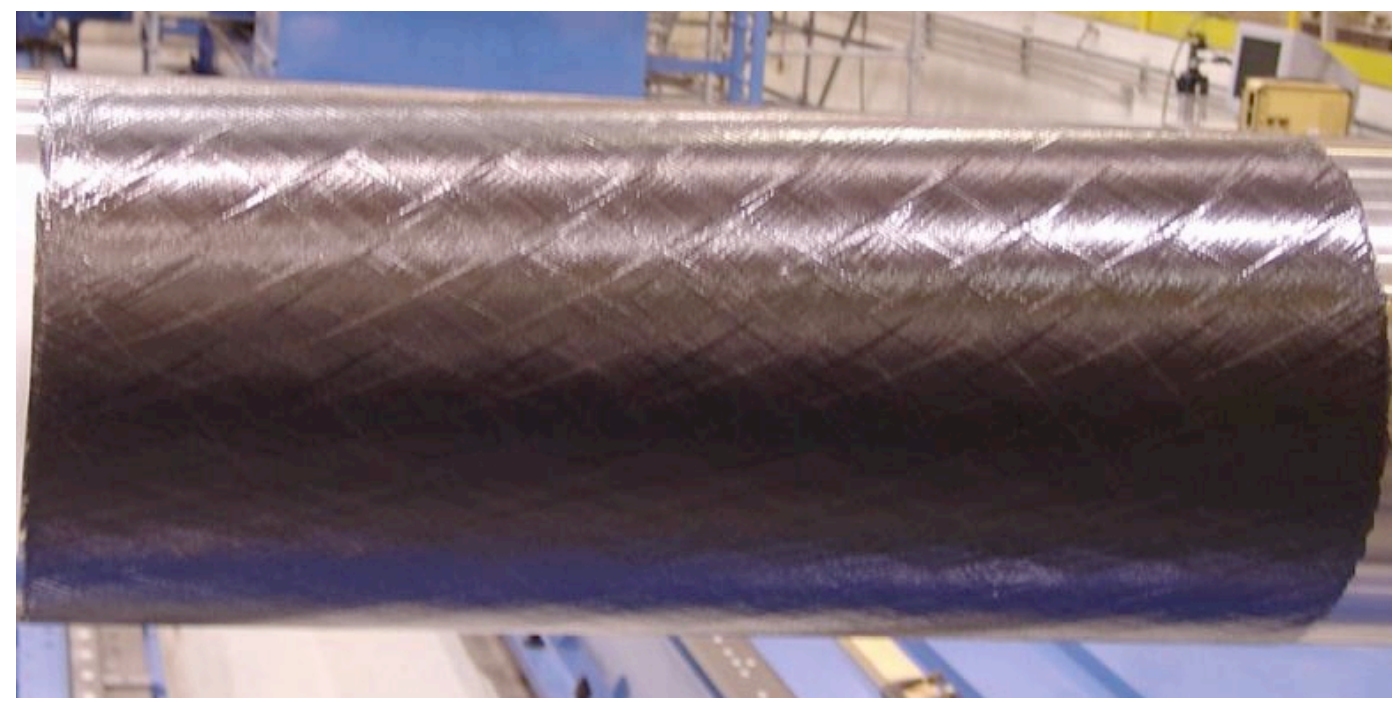

Figure 10. Shell with overlaps on FPM.

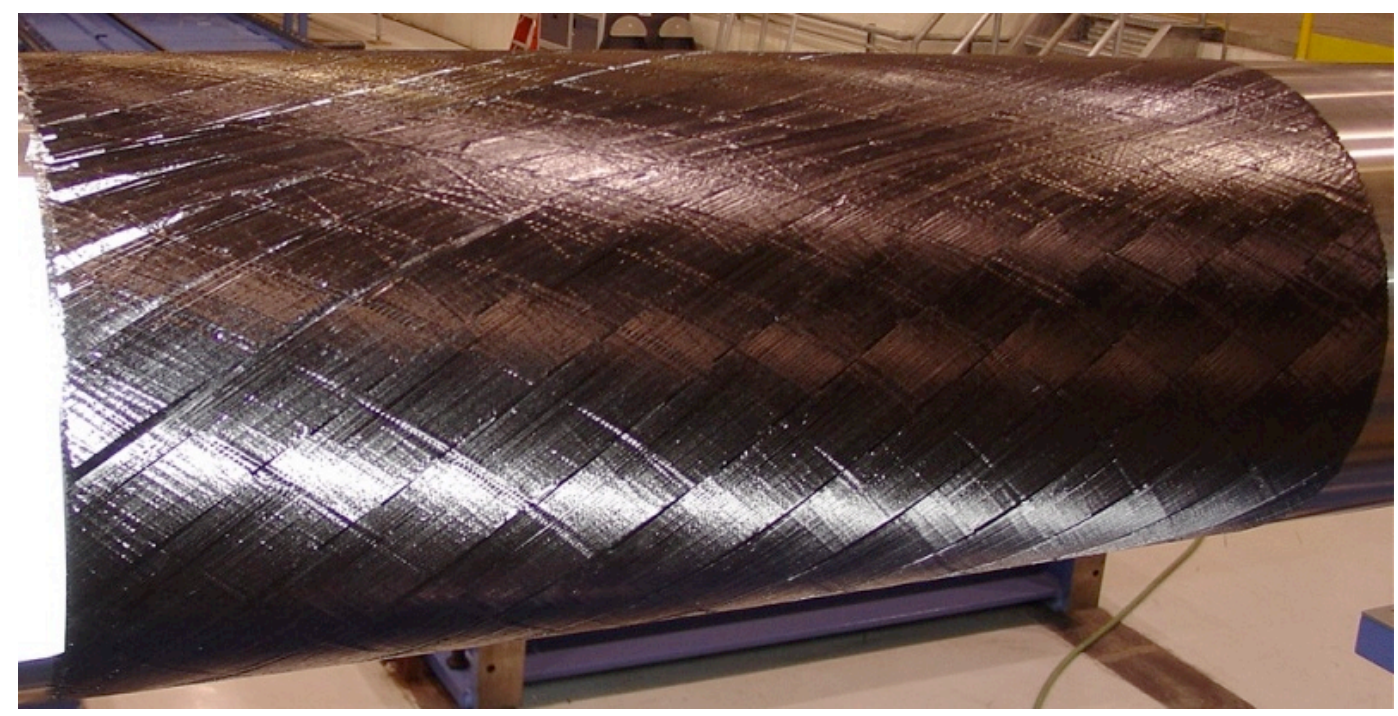

Figure 11. Shell without overlaps on FPM.

American Institute of Aeronautics and Astronautics 
After fiber placement of the shells on the mandrel was completed (see Figures 10 and 11), the shells were then bagged for cure using standard practices (see Figure 12). The bags consisted of A5000 solid release film, 4819 bleeder, N10 breather, J-type thermocouples, air dam, edge dam, SM 5127 tacky tape and WN 1500 bagging film. A vacuum bag integrity test was performed before curing, and the bags passed by holding an acceptable vacuum over a ten minute time period. The shells were cured in Lockheed Martin's $10 \mathrm{ft}$-diameter autoclave, shown in Figure 13, using a cure cycle recommended by the material vendor. The shells were visually inspected after cure, but ultrasonic NDE was not a contract requirement. The completed shells (see Figures 14 and 15) were then packaged and shipped to NASA Langley for further evaluation.

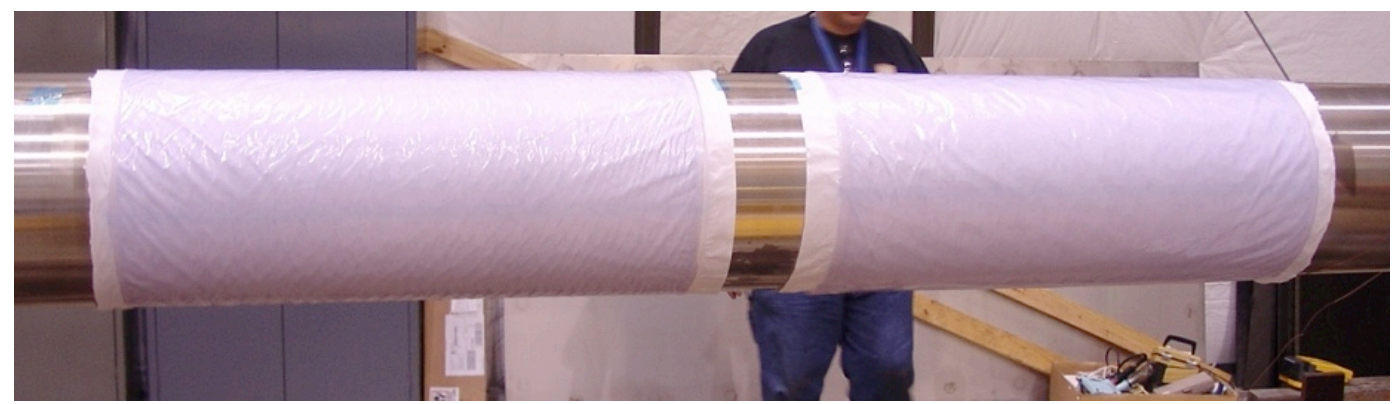

Figure 12. Shells being bagged before cure.

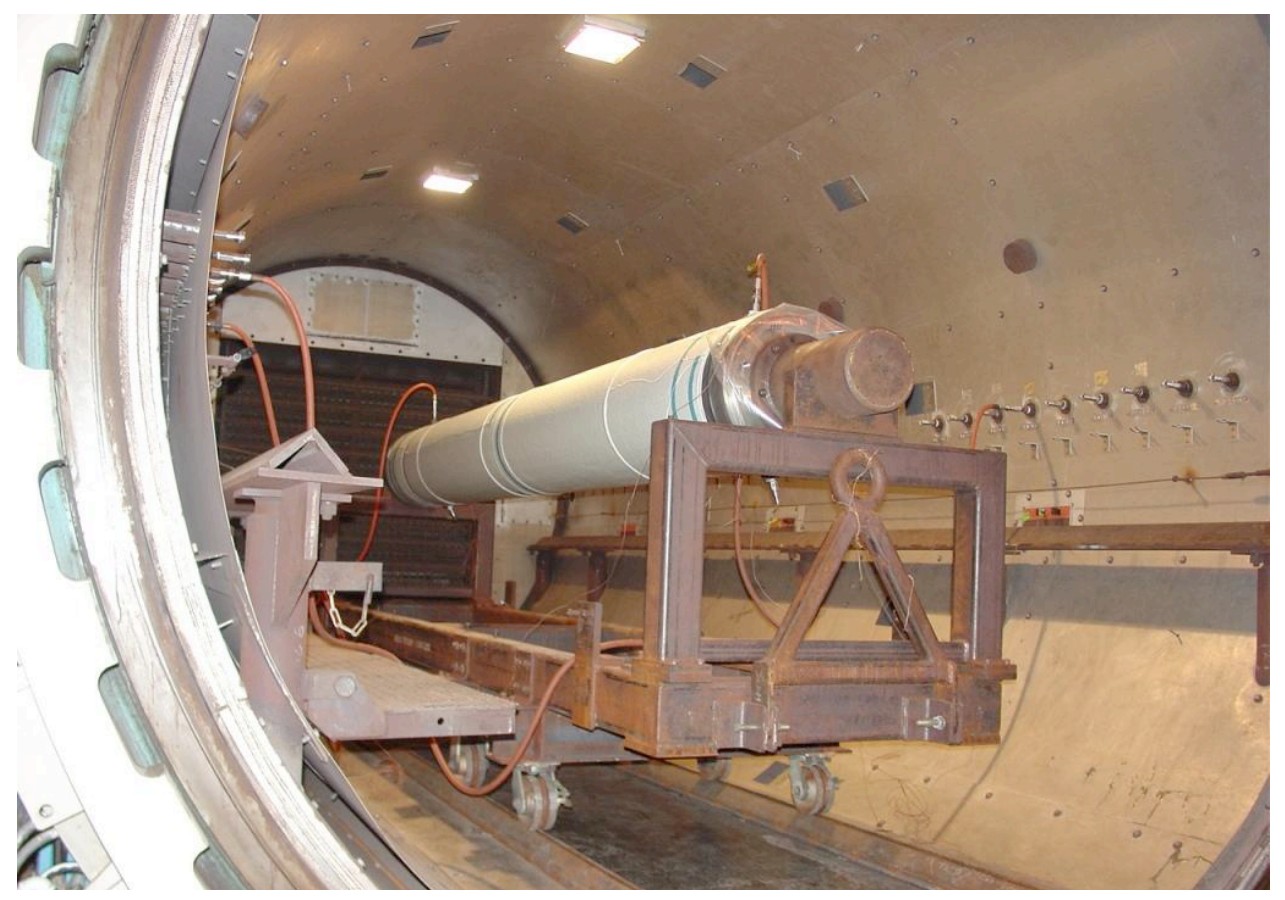

Figure 13. Shells loaded in the autoclave for curing.

\section{Manufacturing Issues and Problems Encountered}

The fabrication process described in this paper produced some useful lessons for all of the parties involved. During their manufacture, the fiber placement machine steered the tows for the four central plies of each shell layup. To produce the curve and the tow drop options the machine would cut the tows at different points along the course, with the pre-existing motivation for tow dropping being to drop the tows farthest from the course centerline to try to minimize fiber orientation angle variations from the ideal values. However, after a tow is cut, the machine is not able to control its placement for the last 1.5 inch that feeds out of the head, so as the machine continues to steer 
along the course, the cut tow does not follow the new steered course and tends to diverge from its intended path. Three unsteered tows that were noted during fabrication of the shell without overlaps are circled in Figure 16. In previous manufacturing trials using curvilinear plies on flat surfaces this effect was not as pronounced, but on the cylindrical shell the convex surface tended to magnify this effect by pushing the tows even further away from the course centerline. This effect was also evident during the manufacture of the shell discussed in Ref. 20, which had a larger tool radius and a smaller effect than the one observed here.

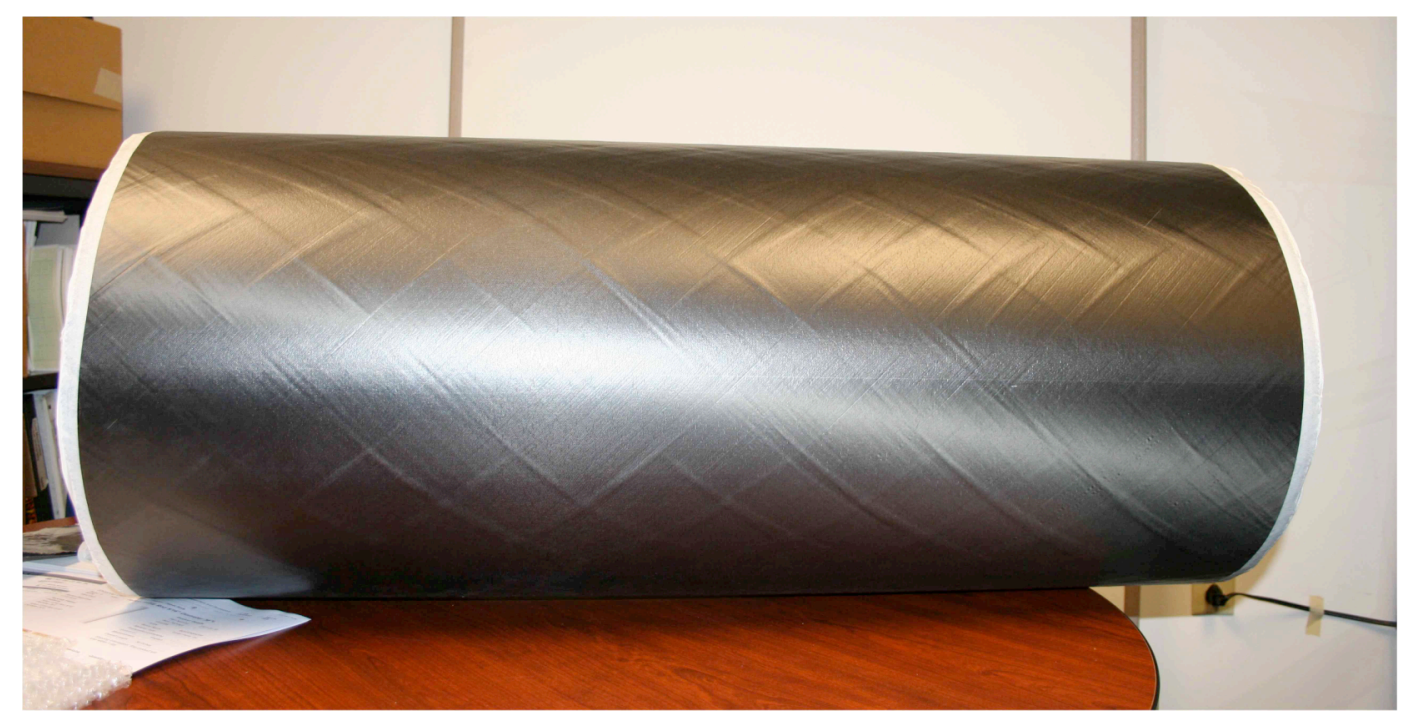

Figure 14. Completed shell with overlaps.

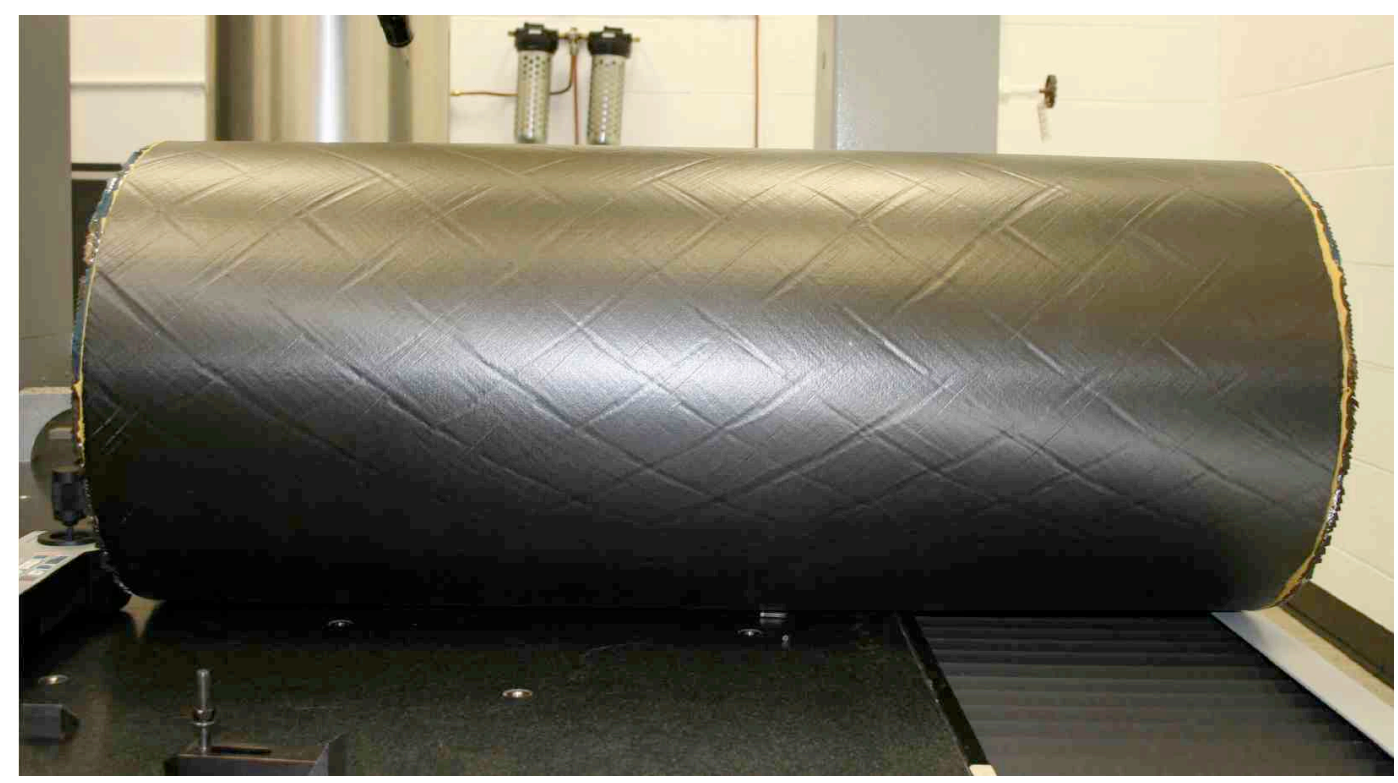

Figure 15. Completed shell without overlaps.

The tows that were dropped on the outside of the curve also made repair more difficult, since it was more difficult to know where to correctly place them back on the shell. The lesson learned here is that it would be better to have all of the tow drops programmed on the inside of the curve as opposed to the earlier technique of dropping the tows farthest from the centerline. Another helpful aid for the touch labor would be to generate a more detailed 
ply book to see actual tows and courses to make any hand rework easier and make sure it is getting replaced in the proper location. The unidirectional fiber placement helped with not losing tows as opposed to bidirectional movement which would have made tows pop off the rollers which the tows have to run through on the fiber placement machine.

The speed at which the shells were placed varied greatly from ply to ply, as the tow-steered plies had to be placed at slower rates than the straight-fiber plies. Initially, kinking of the steered tows was noted when the first tow-steered ply was placed on the mandrel (see Figure 17). This issue was resolved by increasing the head compaction force, slowing the placement speed, and also performing a debulk after each steered ply was placed, which helped the tows stay down in their "unnatural" curved state, but also required extra time and effort during the manufacturing process.

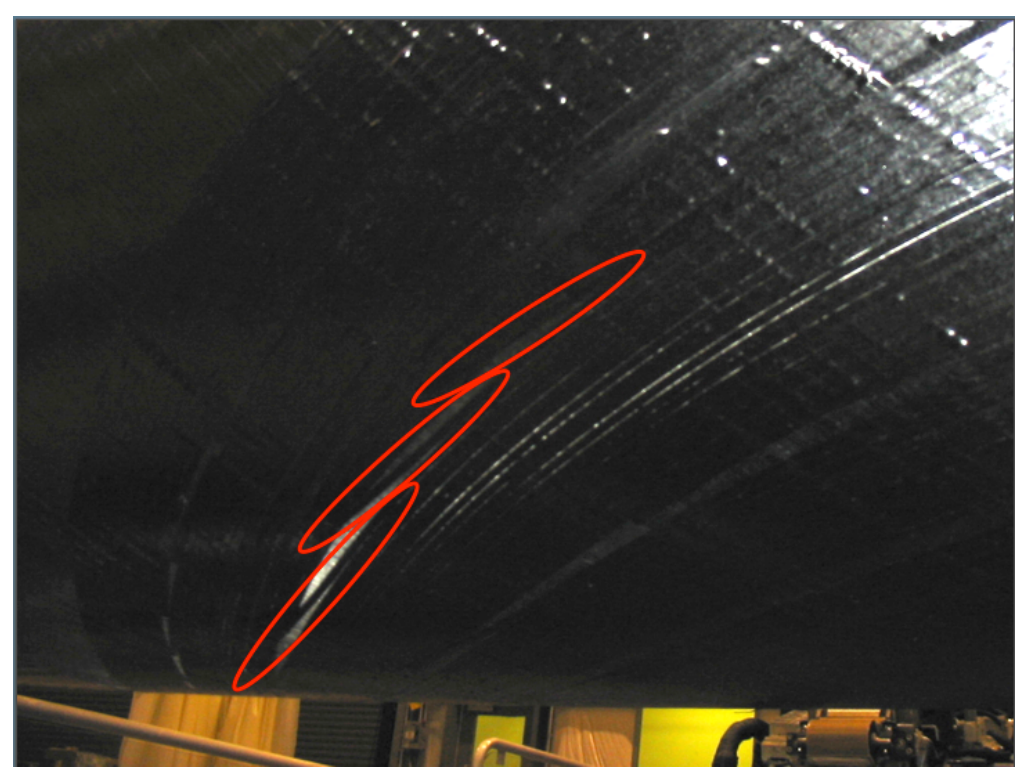

Figure 16. Unsteered tows placed on shell without overlaps.

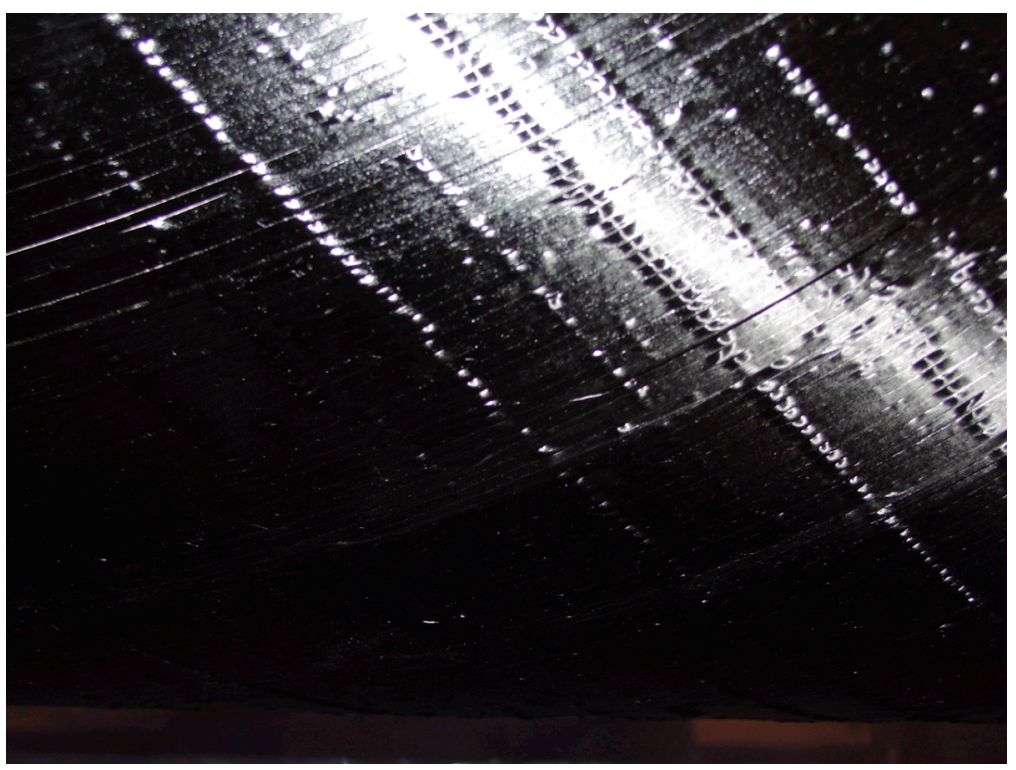

Figure 17. Tow kinking noted during shell fabrication. 
The first shell built also had some difficulty with the off-part motion. That is, when the head finished placing a course, it needed to lift off the tool and move to the starting position of the next course. Ingersoll was made aware of the problem when it occurred, and they fixed the program by changing the code that controls the off-part motion. The mandrel used for fiber placement and curing was hollow, but with sealed ends. The lack of airflow through the interior of the mandrel would affect the air-to-part temperature difference and would throw the cure cycle into holds if not closely monitored.

\section{Shell Surface Surveys}

In order to assess the manufacturing quality of the composite shells the geometry of each shell was measured with a coordinate measurement machine $(\mathrm{CMM})$. The objective of these measurements was to determine the geometric imperfection and thickness variation over the entire surface of both shells. The CMM provides a very accurate means for measurement of panel geometry, and its programmability makes it useful for almost any shell configuration.

\section{A. CMM Measurement Overview}

Geometric imperfection of a shell is defined as the deviation of the mid-plane of the shell wall from the nominal radius while in a stress-free condition. This deviation can be caused by residual and thermal stresses created when the panel was formed, or it may be due to the limitations in the accuracy of the manufacturing process. For these shells the changing material orientation and the presence of tow drops and overlaps also contributes to the imperfection shape.

The two different coordinate systems used during the measurement and analysis of the shell are shown in Figure 18. The CMM machine uses a rectangular coordinate system (Figure 18a) exclusively during panel measurement. All scan data going into and out of the CMM is recorded in this coordinate system. The z-axis is oriented along the axis of the cylinder, determined by a best-fit alignment process, with the origin being located at the center of the cylinder. The $\mathrm{x}$-axis is oriented perpendicular to the z-axis, and passes through a user-defined zero-degree reference. It is logical to use a cylindrical coordinate system for post-processing and analysis of the measurement data. So, a shell coordinate system (see Figure 18b) is defined for this purpose. The X-coordinate defines a point's axial location and the $\mathrm{Y}$-coordinate defines its circumferential location in degrees. The direction of positive $\mathrm{Y}$ is defined such that the radial outward normal is positive using the right-hand rule.

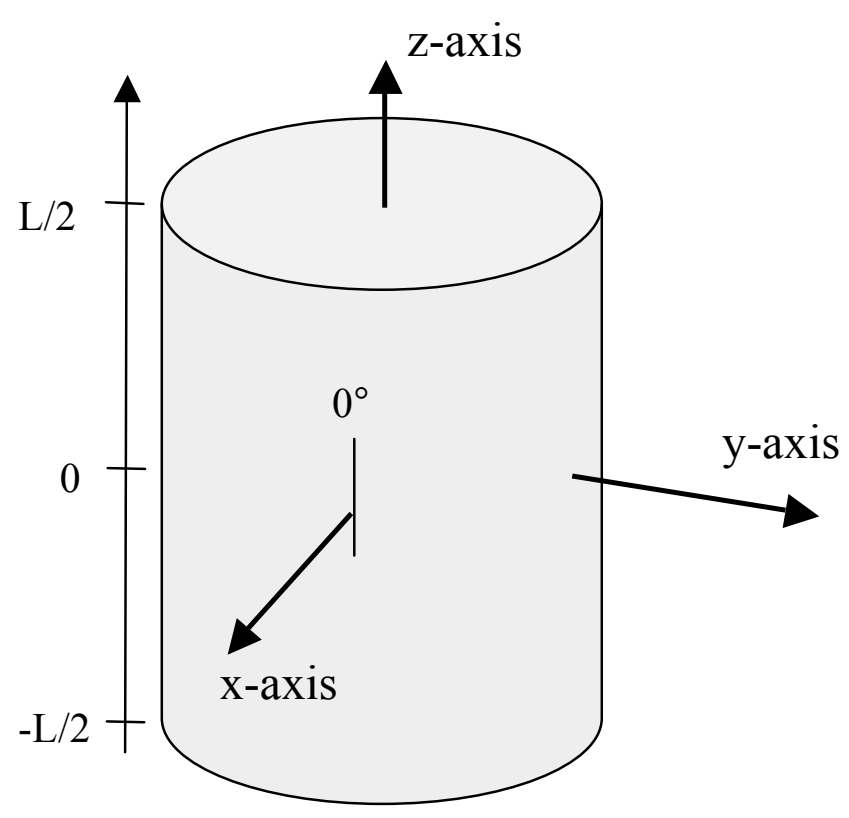

(a) CMM coordinate system

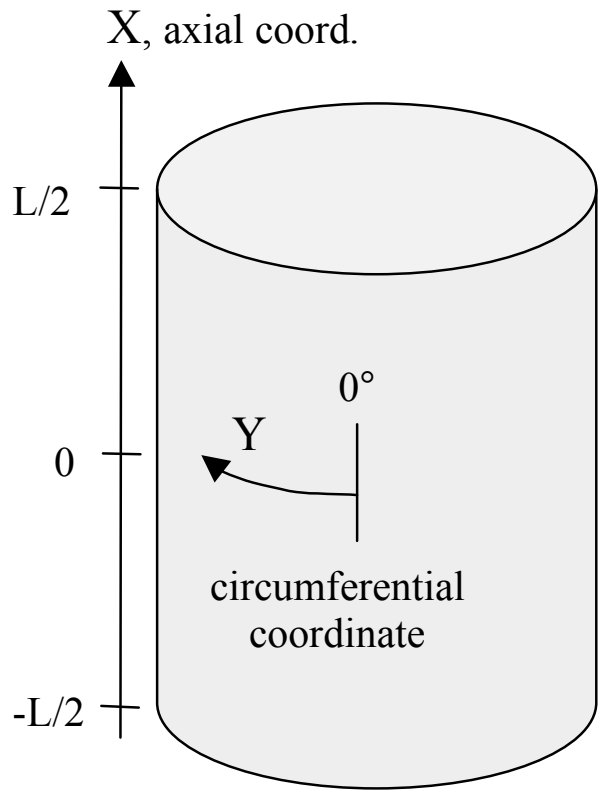

(b) Coordinate system for results

Figure 18. Coordinate systems used for evaluation of tow-steered shells. 
The shells were measured using a Brown and Sharpe Global Image CMM, and PC-DMIS version 3.7 automation software. The primary feature of this CMM is its ability to perform smooth, continuous scans across the surface of an object, thereby reducing the time required to obtain a detailed measurement of the surface contour. The CMM probe was a SP600M equipped with a $50 \mathrm{~mm}$ extension and a $20 \mathrm{~mm}$ by $4 \mathrm{~mm}$ spherical ruby tip. A special purpose PC-DMIS program was written to measure arbitrarily sized cylindrical shells and give the user the ability to control the scan point density of the measurement data. This program is a modification of the panel measurement program described in Ref. 22. The scan lines were spaced every 0.75 degrees around the circumference of the shells (equal to 0.107 inches of arc based on the nominal 8.133-in. mandrel radius), with scan data taken every 0.1 inches along the length of the shell.

After the shells were scanned, the measurement data was then post-processed using a FORTRAN program to give initial geometric imperfection and thickness data for each shell. During post-processing, the entire sets of points measured on both surfaces were used to determine best-fit cylinders for the inner and outer surfaces of the shell. The difference between the best-fit inner and outer surfaces established the average wall thickness. Using the origin of the best-fit inner and outer surfaces, the measured scan data was converted into cylindrical coordinates, and the new radial coordinates were used to calculate the local thickness and imperfection. The shell geometric imperfection was calculated as the difference between the measured inner surface radius and the best-fit inner surface radius, with a positive imperfection indicating that the local inner surface radius is greater than the best-fit radius. The inner surface of the shell was chosen as a reference surface since the mandrel produced a very smooth surface. The thickness was then obtained by subtracting the radii of opposing scan points on the inner and outer surfaces. Eccentricity values were also calculated which give the difference between the measured mid-surface location and a reference surface based on the inner surface.

\section{B. Composite Shell Results}

The measured geometric imperfections and thicknesses of the shell with overlaps are shown as contour plots in Figures 19a and 19b respectively. The inner surface reference radius was measured as 8.144 inches, which is slightly larger than the nominal mandrel radius of 8.133 inches. The geometric imperfections varied between -0.045 and +0.033 inches, with a mean value of zero and a standard deviation of 0.021 inches. The zero-amplitude imperfection contours are plotted as dashed lines in Figure 19a. The shell wall thicknesses varied from 0.032 to 0.086 inches, with an average thickness of 0.050 inch and a standard deviation of 0.011 inches. The pattern of tow overlaps is clearly shown in the thickness measurement, and matches well with the predicted overlap pattern reported in Ref. 21. The measured thicknesses of the shell sides are within 5 percent of the nominal 0.042 -in. shell thickness (based on an 8-ply layup of 0.0052 in.-thick plies), but both the crown and keel are nearly twice the nominal thickness due to the ply overlaps.

The measured geometric imperfections and thicknesses of the shell without overlaps are plotted in Figures 20a and $20 \mathrm{~b}$ respectively. The inner surface reference radius of this shell is 8.146 inches, and the geometric imperfections varied between -0.049 and +0.059 inches, with the extreme values occurring near the free ends of the shell. The standard deviation of the imperfections is 0.019 inches, which is slightly smaller than for the shell with overlaps. Contours with zero amplitude are indicated with the dashed lines in Figure 20a. The shell wall thicknesses varied from 0.022 to 0.059 inches, with an average thickness of 0.039 inch and a standard deviation of 0.002 inches. The gaps between the courses are clearly visible, with the largest gaps located along the sides of the shell at 90 and 270 degrees orientation. The thinnest shell wall locations correspond to the highest concentration of tow drops described in Ref. 21. Some of these gaps are over 0.015 inches deep, and result in a local wall thickness that approaches half of the nominal wall thickness. Also, the thickness measurement shows a number of small ridges. Some of these ridges formed next to ply gaps, while others appear result from a small amount of overlapping between adjacent courses.

To help perform a qualitative assessment of the cured shapes of these shells, quantitative data from the contour plots are replotted to the same scale in Figure 21 . The average measured imperfections at the ends $(\mathrm{X}= \pm 17$ in., solid line) and quarter-points $(\mathrm{X}= \pm 8.5 \mathrm{in}$., long-dashed line) of both shells are plotted along with corresponding values around the shell mid-plane $(X=0$ in., short-dashed line). All plotted imperfection data are first multiplied by a factor of 50 to exaggerate their relative amplitudes with respect to the 16 in.-diameter circle in the figure.

Imperfections for the shell with overlaps are highly symmetric with respect to the crown-keel and side-to-side lines, as well as the shell mid-plane (which can also be seen in Figure 19a). The ends of the shell with overlaps have a parallelogram-like cross-section with rounded corners, dimpled edges and a long axis oriented along the crownkeel line, as illustrated in Figure 21a. The center region of the shell shows an oval cross-section with dimpled sides and a similar orientation of their major axes. The axially stiff crown and keel have similar imperfections along the entire shell length, while the sides show a pronounced inward curvature towards the shell center. 


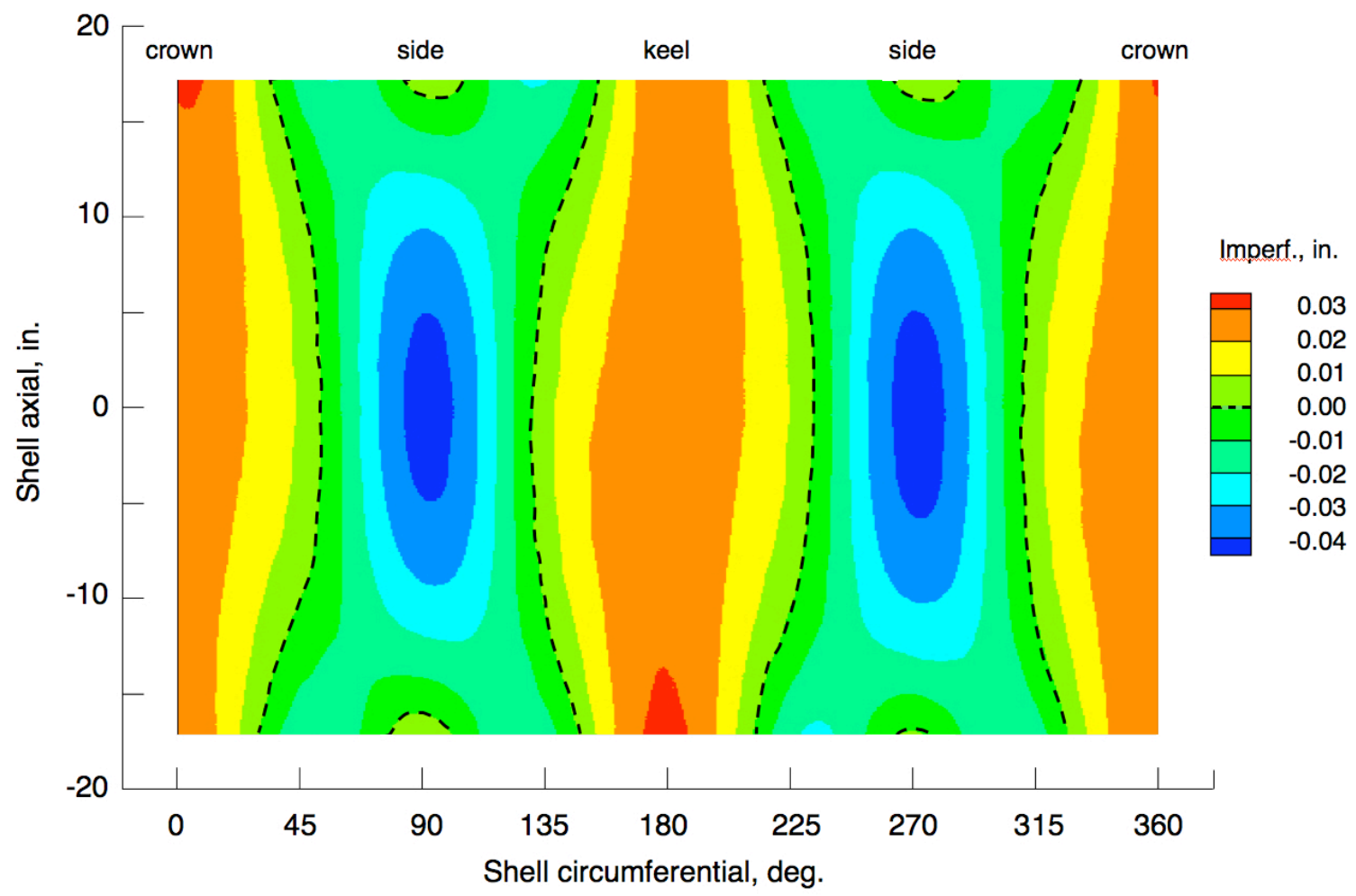

(a) Geometric imperfections

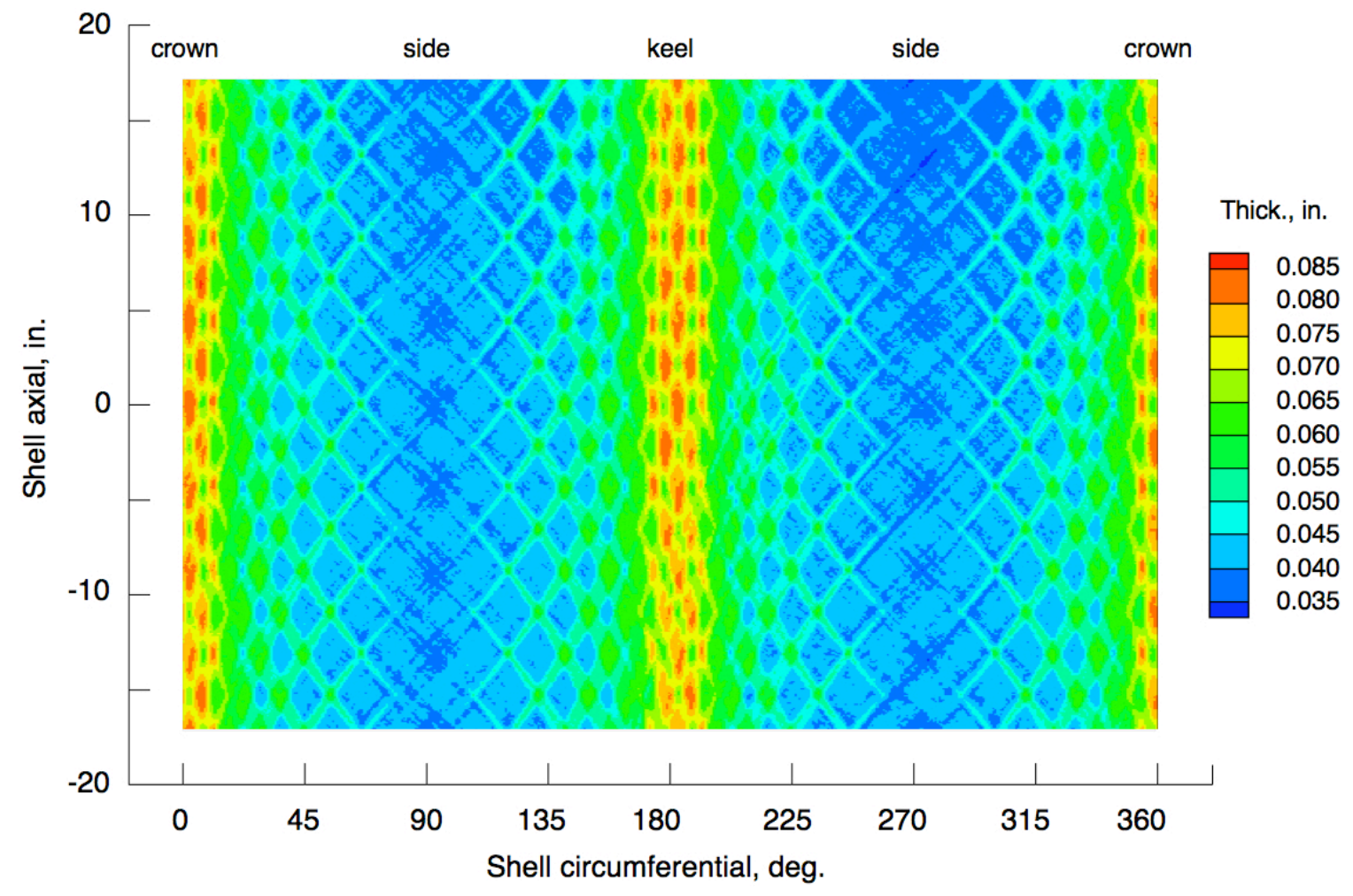

(b) Laminate thicknesses

Figure 19. Measured results for shell with overlaps. 


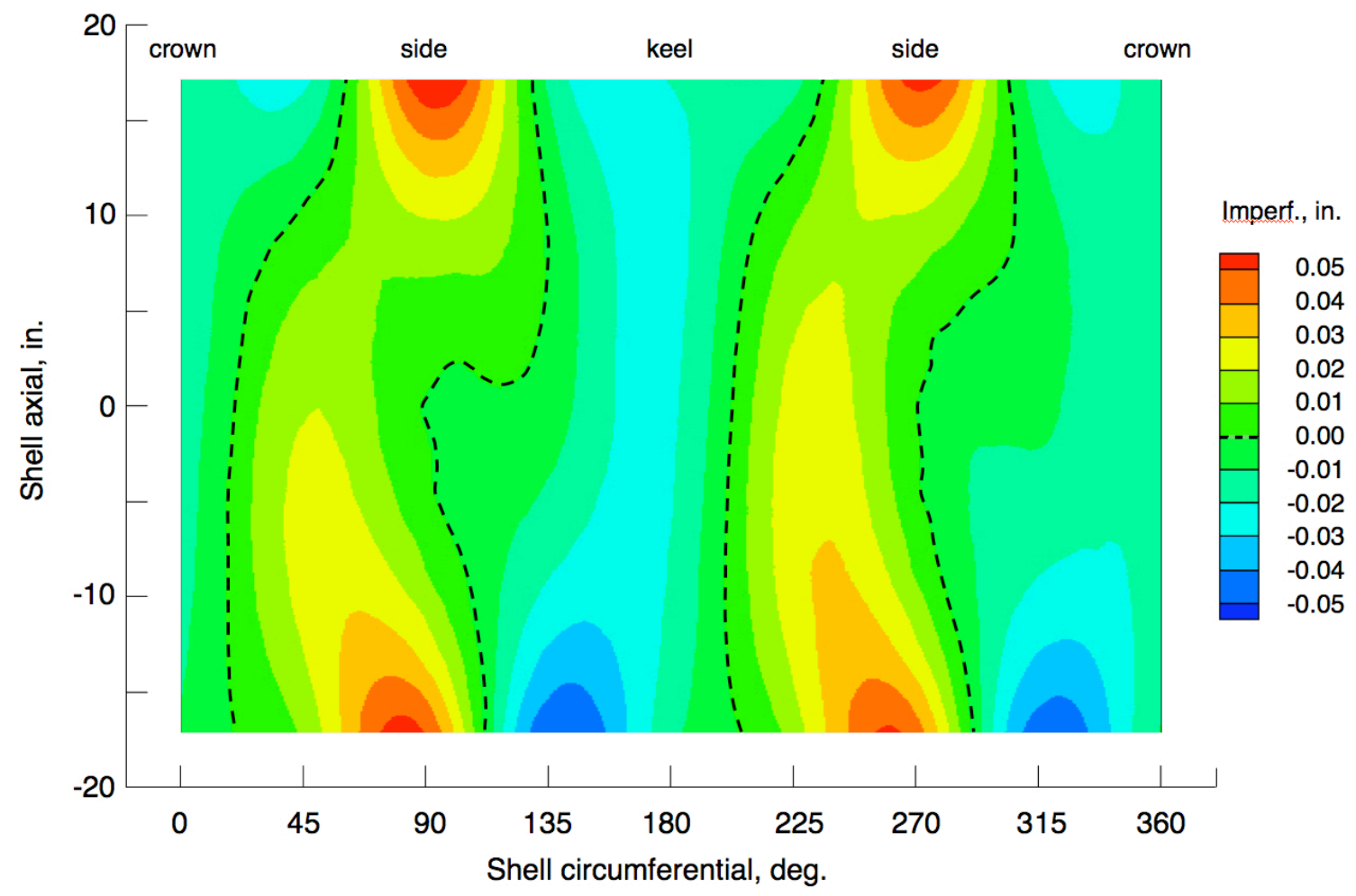

(a) Geometric imperfections

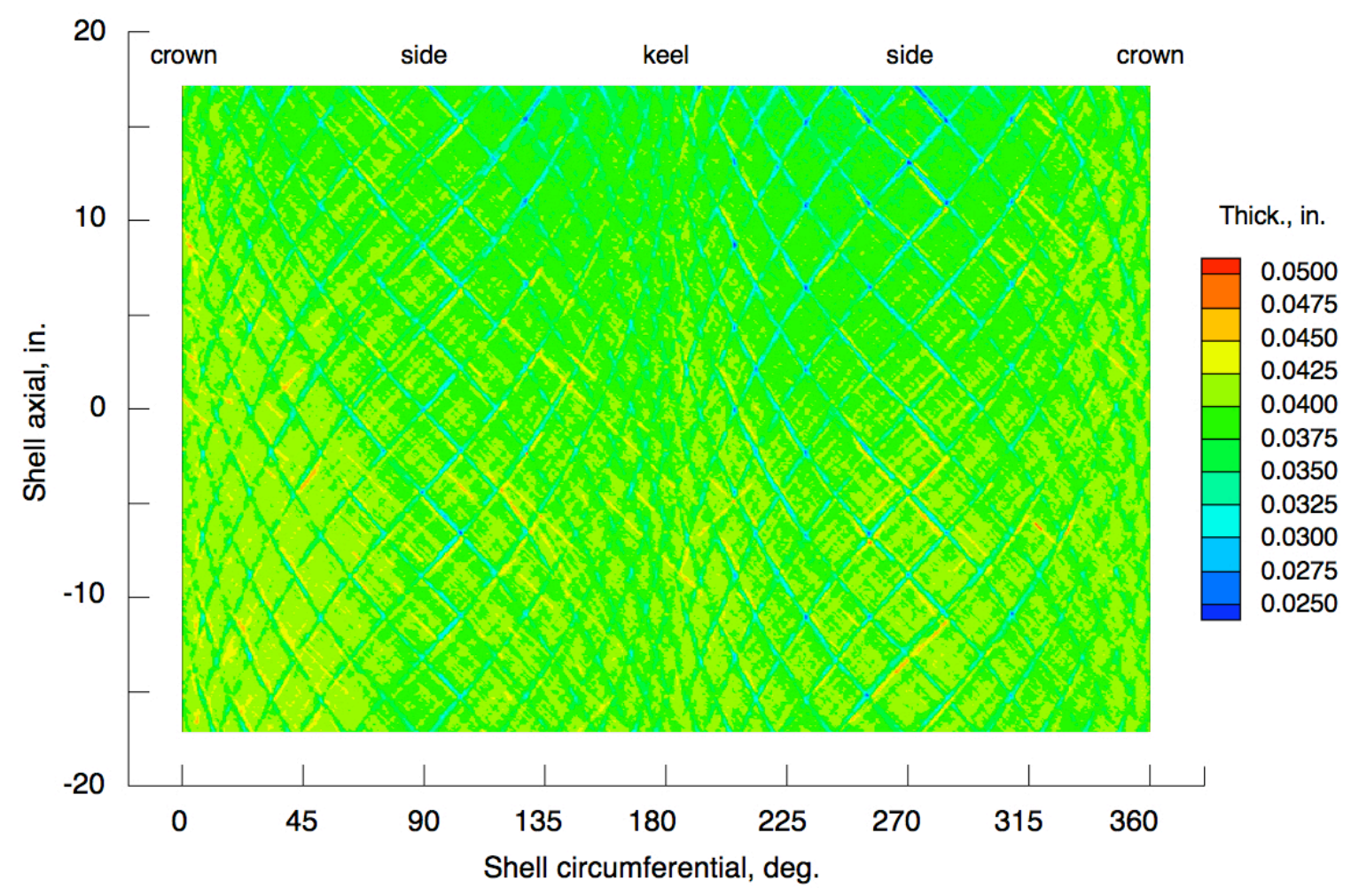

(b) Laminate thicknesses

Figure 20. Measured results for shell without overlaps. 
The imperfections for the shell without overlaps in Figure 20a show little of the symmetry noted above for the shell with overlaps. While the imperfections at the shell ends and quarter-points are not highly symmetric about the shell mid-plane, they still allow qualitative comparisons to be made. The averaged shell ends resemble a lumpy ellipsoid with its minor axis oriented along the crown-keel line. Inward dimples are noted along all four edges, with larger amplitudes along the 135-315 degree axis in Figure 21b. The imperfection data towards the middle of this shell are all slightly ovoid, with much smaller amplitudes than at the ends. These shapes are oriented with their major axes along the 45-225 degree axis. Imperfection trends for the shell without overlaps are nearly identical to those discussed above, with essentially uniform displacements along the crown and keel lines along the shell length and a slight inward orientation. The shell sides also show pronounced inward dimples towards the shell center.

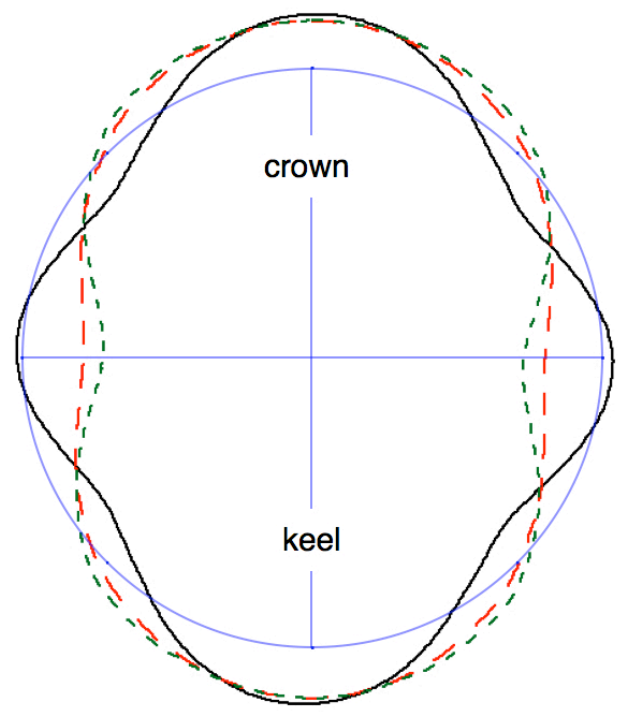

(a) Shell with overlaps

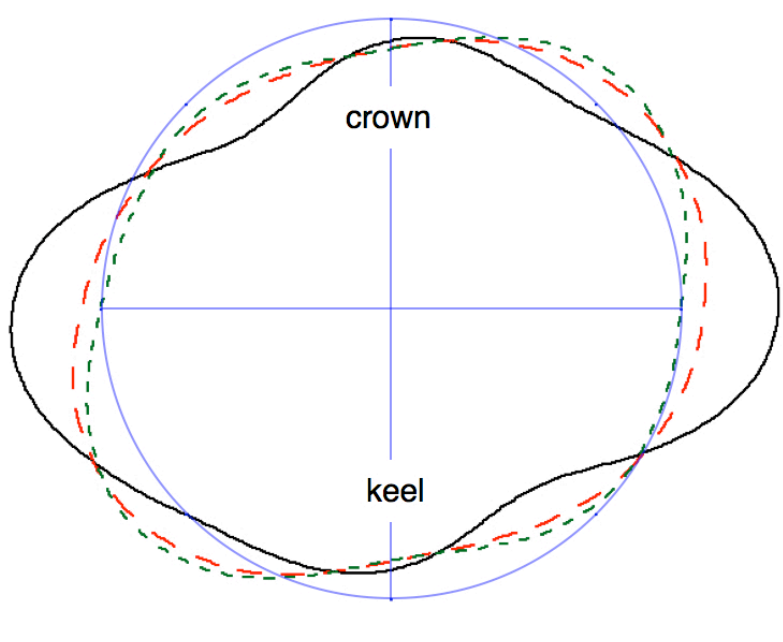

(b) Shell without overlaps

Figure 21. Qualitative comparison of imperfections for tow-steered shells.

The measured thickness data for the shells with and without overlaps were further analyzed to determine their frequency distribution. The shell thickness data were sorted into 0.0002-in. increments, and the percentage of the entire data set that fell within each increment is plotted in Figure 22 against that increment. Results for the shell with overlaps are shown as a solid line in this figure, and show three large peaks centered at $0.0405,0.0503$ and 0.0605 inches, which correspond, respectively, to the 8-ply laminates along the shell sides and the 10- and 12-ply curved overlap regions located between the sides and crown and keel. Two much lower peaks at 0.0715 and 0.0787 inches are associated with the thicker 14- and 16-ply overlaps along the crown and keel. The corresponding data for the shell without overlaps are plotted as a dashed line that has one large peak with a maximum at 0.0397 inches, which is very close to the 0.039 -in. average shell thickness reported above. The 6 -fold difference in the standard deviations of the two shells is clearly reflected in this plot, with much smaller variation of the thicknesses for the shell without overlaps.

One of the primary difficulties that existed when measuring these shells was ensuring that they were in a stressfree state while they were being measured by the CMM. The relatively thin walls of the shells meant that they were noticeably flexible, and the possibility existed that each time the shell was placed on the measurement table its geometry would be slightly different. If this were the case then the shell would not be in a natural state while it was being measured, and the imperfection measurements would not be as meaningful. To verify the repeatability of the measurements, each shell was measured several times, twice for the shell with overlaps, and three times for the thinner shell without overlaps. Between each measurement the shell was removed from and placed back on the CMM. The imperfection measurement results showed a variation of less than 0.003 in. for the shell with overlaps and a variation less than $0.001 \mathrm{in}$. for the shell without overlaps. Based on these results, it was concluded that the shells had sufficient stiffness for the measurements of the geometric imperfections to be considered reliable. 


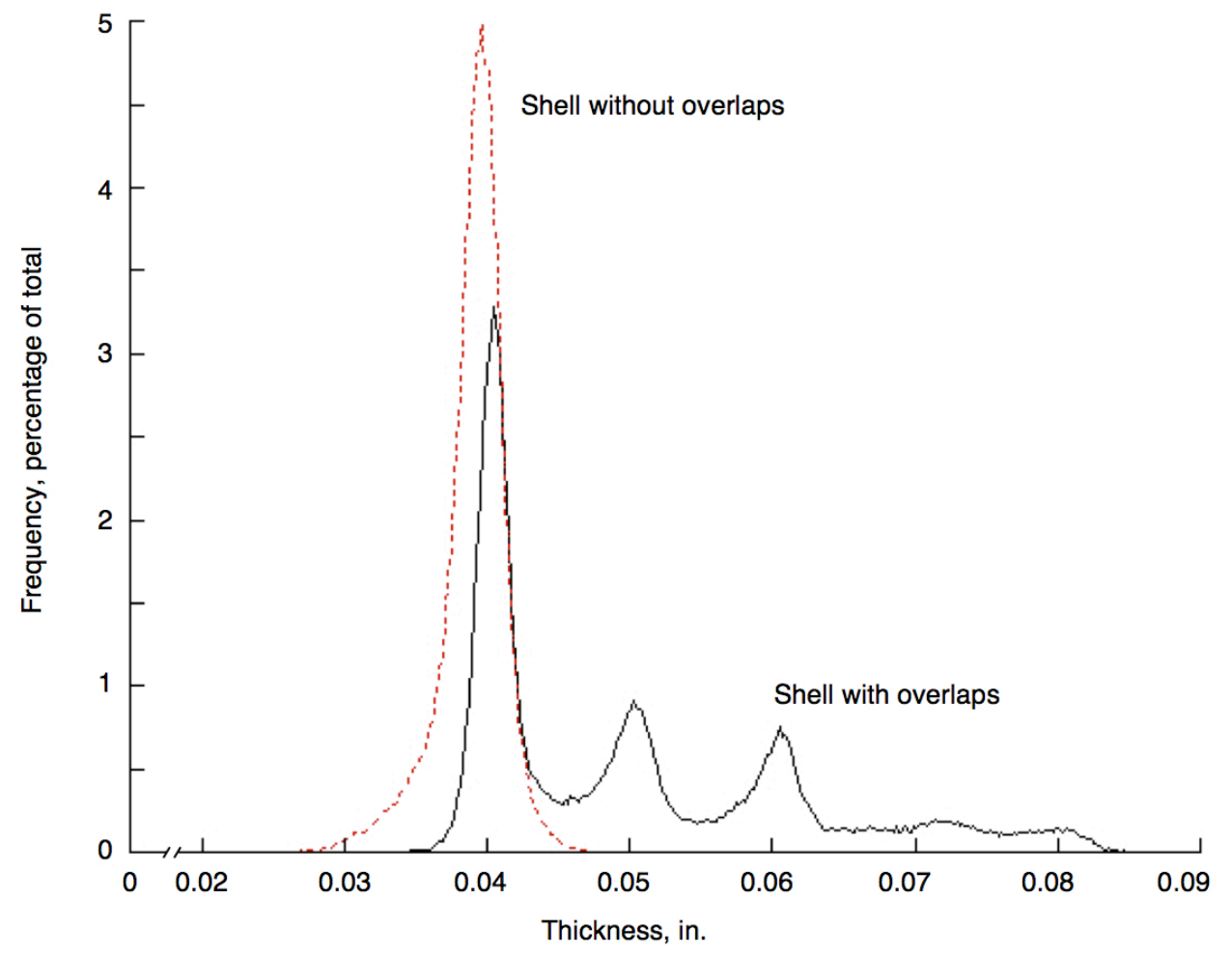

Figure 22. Laminate thickness distribution for tow-steered shells.

\section{Concluding Remarks and Future Plans}

This paper presents results from a joint NASA-industry study to design and manufacture two composite shells with advanced, tow-steered layups. Small changes in the nominal circumferential spacing and fiber orientation angles of the curvilinear steered paths were made during their detailed design and programming for implementation on the fiber placement machine. These changes were designed to better conform to the desired shell geometry and minimize the course-to-course gaps on the shell without overlaps.

Fabrication of the two tow-steered shells using the fiber placement machine was successfully accomplished, and the shells were cured in an autoclave at the manufacturer-recommended conditions. One unexpected issue encountered during the manufacturing process was the presence of waves or bumps in the placed tows. This was addressed by debulking the laminate between plies, slowing the placement rate, and increasing compaction force.

Post-fabrication surface surveys were performed on the cured shells' inner and outer surfaces to determine their initial imperfections and thickness variations. Both shells' cured cross sections vary along their length, and are generally elliptical with the major axes rotated 90 degrees between the shells with and without overlaps. Surprisingly, the gaps between adjacent courses where tows are dropped on the shell without overlaps are more prominent than was predicted during their design.

Current plans call for further analyses and testing of the tow-steered shells to be performed at NASA Langley. Detailed finite element models of the shells will be developed which include the measured laminate thicknesses and initial imperfections described above, after which both linear and geometrically nonlinear analyses will be performed to predict the shell structural response to various applied loads. The tow-steered shells will be instrumented and have the end fittings attached, and they will then be tested under quasi-static shear, bending and torsion loads in a combined-loads test facility. These initial tests will be performed to some small fraction of the analysis-predicted failure loads, after which the shells will be tested to failure under an applied bending moment.

\section{References}

1 Evans, D. O., Vaniglia, M. M. and Hopkins, P. C., "Fiber Placement Process Study," 34th International SAMPE Symposium, Vol. 34, Book 2, May 1989, pp. 1822-1833. 
2 Buchanan, D. L., Alexander, R. A. and Thomas, J. A., "Structural Design of a Fiber Placed Inlet Duct," 40th AIAA/ASME/ASCE/AHS/ASC Structures, Structural Dynamics and Materials Conference, 1999, AIAA paper no. 1999-1442.

${ }^{3}$ Hyer, M. W. and Charette, R. F., "The Use of Curvilinear Fiber Format in Composite Structure Design," 30th AIAA/ASME/ASCE/AHS/ASC Structures, Structural Dynamics and Materials Conference, 1989, AIAA paper no. 1989-1404.

${ }^{4}$ Hyer, M. W. and Lee, H. H., "The Use of Curvilinear Fiber Format to Improve Buckling Resistance of Composite Plates with Central Circular Holes," Composite Structures, Vol. 18, No. 3, 1991, pp. 239-261.

5 Gürdal, Z. and Olmedo, R., "In-Plane Response of Laminates with Spatially Varying Fiber Orientations: Variable Stiffness Concept," AIAA Journal, Vol. 31, No. 4, 1993, pp 751-758.

6 Olmedo, R. and Gürdal, Z., "Buckling Response of Laminates with Spatially Varying Fiber Orientations," 34th AIAA/ASME/ASCE/AHS/ASC Structures, Structural Dynamics, and Materials Conference, 1993, AIAA paper no. 1993-1567.

7 Gürdal, Z. "Design of Variable Stiffness Panels," 10th DOD/NASA/FAA Conference on Fibrous Composites in Structural Design, Vol. I, 1994, Report no. NAWCADWAR-94096-60.

8 Waldhart, C., Gürdal, Z. and Ribbens, C., "Analysis of Tow Placed, Parallel Fiber, Variable Stiffness Laminates," 37th AIAA/ASME/ASCE/AHS/ASC Structures, Structural Dynamics, and Materials Conference, 1996, AIAA paper no. 1996-1569.

9 Tatting, B. F., "Analysis and Design of Variable Stiffness Composite Cylinders," Ph.D. Dissertation, Virginia Polytechnic Institute and State University, Blacksburg, VA, 1998.

${ }^{10}$ Langley, P. T., "Finite Element Modeling of Tow-Placed Variable-Stiffness Composite Laminates," M.S. Thesis, Virginia Polytechnic Institute and State University, Blacksburg, VA, 1999.

11 Tatting, B. F. and Gürdal, Z., "Design and Manufacture of Tow-Placed Variable Stiffness Composite Laminates with Manufacturing Considerations," 13th U.S. National Congress of Applied Mechanics, 1998.

12 Tatting, B. F. and Gürdal, Z., "Design and Manufacture of Elastically Tailored Tow Placed Plates," NASA/CR-2002-211919, 2002.

13 Tatting, B. F. and Gürdal, Z., "Automated Finite Element Analysis of Elastically-Tailored Plates," NASA/CR-2003-212679, 2003.

14 Jegley, D. C., Tatting, B. F. and Gürdal, Z., "Tow-Steered Panels with Holes Subjected to Compression or Shear Loading," 46th AIAA/ASME/ASCE/AHS/ASC Structures, Structural Dynamics and Materials Conference, 2005, AIAA paper no. 2005-2081.

$15 \mathrm{Wu}$, K. C. and Gürdal, Z., "Variable Stiffness Panel Structural Analyses with Material Nonlinearity and Correlation with Tests," 47th AIAA/ASME/ASCE/AHS/ASC Structures, Structural Dynamics and Materials Conference, 2006, AIAA paper no. 2006-2165.

16 Ilcewicz, L. B. and Murphy. B., "Safety \& Certification Initiatives for Composite Airframe Structure," 46th AIAA/ASME/ASCE/AHS/ASC Structures, Structural Dynamics \& Materials Conference, 2005, AIAA paper no. 2005-1877.

17 Achary, D. C., Biggs, R. W., Bouvier, C. G., McBain, M. C. and Lee, W. Y., "Composite Development \& Applications for Cryogenic Tankage," 46th AIAA/ASME/ASCE/AHS/ASC Structures, Structural Dynamics \& Materials Conference, 2005, AIAA paper no. 2005-2160.

18 Riddick, J. C. and Hyer, M. W., "The Response of Segmented-Stiffness Composite Cylinders to Axial Endshortening," Composite Structures, Vol. 40, No. 2, 1998, pp. 103-114.

19 Riddick, J. C. and Hyer, M. W., "Postbuckling Behavior of Segmented Circular Composite Cylinders," AIAA Journal, Vol. 42, No. 1, 2004, pp. 185-195.

20 Blom, A. W., List, J., Stickler, P. B., and Gürdal, Z., "Design and Manufacture of a Composite Cylinder with Circumferentially Varying Stiffness," American Society for Composites 23rd Technical Conference, 2008.

$21 \mathrm{Wu}, \mathrm{K} . \mathrm{C}$., "Design and Analysis of Tow-Steered Composite Shells Using Fiber Placement," American Society for Composites 23rd Technical Conference, 2008.

22 Thornburgh, R. P., "Imperfection and Thickness Measurement of Panels Using a Coordinate Measurement Machine,"NASA/TM-2006-213954, ARL-TR-3717, 2006. 